\title{
A INTEGração Vertical DO CRIME ORGANIZADO Relacionada CORRUPÇÃo Política: ANÁLISE JURÍDICO-ECONOMÉTRICA DO CONFISCO DE BENS E DiREITOS HuMANOS*
}

\author{
EDGARDO BUSCAGLIA ${ }^{\dagger}$
}

\section{UM DOSSIÊ SOBRE ANÁlise ECONÔMICA DO DIREITO}

RESUMO: A análise apresentada neste estudo demostra que níveis elevados de integração vertical de organizações criminosas no âmbito jurídico-econômico - no qual, por exemplo, uma rede criminosa transnacional desenvolve a capacidade de licitamente gerar suas próprias matérias-primas, produzindo, transportando e distribuindo os bens ou

\footnotetext{
* Traduzido do inglês para o português, com a autorização do autor, por Jean R. R de Pontes e revisado por Luciana Silveira, do texto The Vertical Integration of Organized Crime Linked to Political Corruption: An Economic Analysis of Asset Forfeitures and Human Rights. Jean R. R. de Pontes é Mestrando pelo Programa de Pós-Graduação em Direito da Universidade do Estado do Rio de Janeiro (PPGD/UERJ) e Pesquisador do Laboratório de Estudos Teóricos e Analíticos sobre Comportamento das Instituições (LETACI). E-mail: jean.pontes@simoespontes.com.br. Luciana Silveira é Mestranda pelo Programa de Pós-Graduação em Direito da Universidade Federal do Rio de Janeiro (PPGD/UFRJ) e Pesquisadora do Laboratório de Estudos Teóricos e Analíticos sobre o Comportamento das Instituições (LETACI). E-mail:

lucianasilveirardente@gmail.com.

${ }^{\dagger}$ Diretor do International Law and Economic Development Center da University of Virginia e Pesquisador Sênior em Law \& Economics na Columbia University, EUA, Professor Visitante na National University of Buenos Aires e na Universidad Nacional del Sur, Argentina, e Presidente do Instituto de Acción Ciudadana, México.
} 
serviços que posteriormente serão traficados, bem como controlando seu comércio atacadista ou varejista - estão sempre relacionados à corrupção política no financiamento de campanhas eleitorais e em contratações públicas, nos países em que falhas estatais mais agudas impedem o desmantelamento legal e judicial de redes criminosas por meio do confisco de ativos. Nesse contexto, esta análise amplia conclusões anteriores, fornecendo bases conceituais e empíricas para explicar a maior diversificação dos crimes econômicos organizados e sua relação com um maior grau de integração vertical em negócios jurídicos politicamente resguardados por financiamentos ilícitos de campanhas eleitorais e envolvimentos ilegais em licitações de contratos públicos. Com base nas estruturas teóricas de Williamson, observa-se que a integração vertical das atividades econômicas pelas organizações criminosas tem por objetivo reduzir os custos de transação ligados à frequência, especificidade, incerteza, racionalidade limitada e comportamento oportunista nas transações de mercado em ambientes econômicos, nos quais outras organizações criminosas também competem com violência e corrupção para conquistar mercados lícitos e apoiar atividades criminosas das mais variadas naturezas. Além disso, os conceitos e dados empíricos ora apresentados demonstrarão que uma maior integração vertical das atividades econômicas de uma rede criminosa em um ambiente em que existem falhas estatais na prestação de serviços públicos (tais como a garantia de transparência e higidez nas eleições políticas e na tomada de decisões judiciais) também será acompanhada do maior fornecimento pelo crime organizado de bens e serviços quase-públicos (como, por exemplo, mecanismos alternativos de resolução de conflitos), voltados a atender aos segmentos economicamente mais vulneráveis da população, localizados nas áreas geográficas de atuação de tais organizações criminosas. Nesse cenário, a violação sistemática dos direitos políticos e civis, tais como a violação do direito humano de acesso à justiça ou à forma transparente e hígida de eleger mandatários de cargos públicos, funciona como um pré-requisito para o fortalecimento social do crime organizado. Em suma, há uma reação em cadeia em que as falhas do sistema judicial incentivam recursos mais frequentes a mecanismos 
alternativos de resolução de conflitos fornecidos pelo crime organizado e por grupos armados, os quais por sua vez estão ligados a uma maior diversificação de mercados ilícitos e a uma maior integração vertical a mercados lícitos que sustentam tais mercados ilícitos. Uma das principais conclusões deste trabalho é que uma atuação judicial mais eficiente no confisco de ativos provenientes de crimes reforça o direito humano de acesso à justiça para os segmentos mais vulneráveis da população, além de impactar positivamente o direito de eleger, com menor interferência do crime organizado, mandatários de cargos públicos. Por conseguinte, uma atuação judicial mais eficiente no desmantelamento de redes criminosas não só reforçará a dissuasão/punição dessas organizações, como também evitará o crescimento de bolhas de proteção sociopolítica, nas quais o crime organizado prospera.

Palavras-Chave: Crime Organizado; Corrupção Política; Confisco de Bens; Sistemas Judiciais; Métodos Alternativos de Resolução de Disputas (ARD).

\begin{abstract}
The analysis presented in this study shows that greater scopes of criminal organizations' vertical integration within the legal economic domains - where, for example, a transnational criminal network acquires the legal economic capacity to generate its own raw materials, produce the goods or services to be later trafficked, transport the goods or services to be trafficked, distribute the good or service and also control the wholesale and retail legal businesses - always come hand in hand with political corruption within the electoral campaign financing and public procurement domains in countries with more acute state failures to legally and judicially dismantle criminal syndicates through asset forfeitures. In this context, this analysis extends previous findings by providing conceptual and empirical foundation to the greater diversification of organized economic crimes associated with a more intense degree of vertical integration in legal businesses that are
\end{abstract}


politically protected through illegally funding electoral campaigns and by engaging in public procurement bids. Building on Williamson's theoretical frameworks, the vertical integration of legal economic activities by criminal enterprises is aimed at the criminal organizations' aim to reduce transaction costs linked to the frequency, specificity, uncertainty, bounded rationality, and opportunistic behaviour in market transactions within economic environments where other criminal organizations also compete with violence and with corruption to capture legal markets in order to support their more diverse criminal activities. Moreover, the theory and empirical verification presented here will show that greater vertical integration of economic activities of a criminal network in the midst of State failures to provide public services (such as state failures in providing clean political elections and court services) will also come hand in hand with the greater organized crime supply of quasipublic goods and services (such as alternative dispute resolution mechanisms) aimed at the demand of the most economically vulnerable segments of the population located within the geographic areas where this same organized crime group operates. In this scenario, a systemic violation of political and civil rights, such as the systemic violation of the human rights to access justice or to cleanly elect public officials, will act as a pre-condition for the social empowerment of organized crime. In short, there is a chain reaction within which judicial system failures foster more frequent provisions of alternative dispute resolution mechanisms supplied by organized crime armed groups that are linked to a greater diversification of criminal markets and a greater vertical integration of legal markets supporting the criminal markets. One of the main implications of this piece is that a more efficient judicial performance in forfeiting criminal assets will strengthen the human right to access justice for the most vulnerable segments of the population and will positively impact on the right to cleanly elect public officials with less organized crime interference. Therefore, a more efficient judicial performance in dismantling criminal networks will enhance punitive/deterrence against criminal enterprises but also prevent the growth of social and political protection bubbles within which organized crime thrives. 
KeYWORDS: Organized Crime; Political Corruption; Forfeiture of Goods; Systems of Justice; Alternative Dispute Resolution Mechanisms (ADR).

\section{SUMÁRIO:}

I. ANTECEDENTES E INTRODUÇÃO........................................................706

II. ANÁLISE JURIMÉTRICA INTERNACIONAL COMPARADA NA EFICIÊNCIA ALOCATIVA DOS SISTEMAS JUDICIAIS .......................716

III. UMA ANÁLISE COMPARATIVA DE PROCESSOS JUDICIAIS E FATORES SOCIAIS LIGADOS À PROCURA POR MARD

IV. A OFERTA DE MARD COMO SUPORTE PARA A INTEGRAÇÃO VERTICAL DAS REDES CRIMINOSAS E A CORRUPÇÃO POLÍTICA .....732

V. CONCLUSÃO ....................................................................................743

VI. REFERÊNCIAS ..........................................................................................746

\section{TABLE OF CONTENTS:}

I. BACKGROUND AND INTRODUCTION.................................................706

II. INTERNATIONAL COMPARATIVE JURIMETRIC ANALYSIS OF THE ALLOCATIVE EFFICIENCY OF JUDICIAL SYSTEMS..............................716

III. A COMPARATIVE ANALYSIS OF JUDICIAL AND SOCIAL FACTORS LINKED TO THE DEMAND FOR ARDMS............................................724

IV. THE SUPPLY OF ARDMS AS SUPPORT FOR THE VERTICAL INTEGRATION OF CRIMINAL NETWORKS AND POLITICAL CORRUPTION....................................................................................................732

V. CONCLUSION .............................................................................................743

VI. REFERENCES …...........................................................................................746 


\section{ANTECEDENTES E INTRODUÇÃO}

A governança política básica, em geral, e as reduções dos níveis de violência coletiva física ou de outros tipos, em particular, exigem que as instituições do setor público e da sociedade civil organizada disponham de mecanismos preventivos eficazes. Para que o Estado de Direito possa ter algum significado, esses mecanismos devem ser imparciais na sua forma de acesso social, a fim de corrigir injustiças com as devidas garantias processuais, assegurando, assim, o exercício dos mais elementares direitos políticos, civis, sociais, culturais e econômicos recomendados em nove Convenções das Nações Unidas sobre Direitos Humanos e seus Protocolos, mundialmente reconhecidos e ratificados. ${ }^{1}$ Nesse contexto, Buscaglia demonstra que um regime de seguridade humana abrangente e eficaz requer a consistente, previsível e coerente aplicação prática de todos os direitos políticos, civis e econômicos de forma efetiva (e não apenas sua proteção teórica no papel). ${ }^{2}$ Os mecanismos legais e judiciais sustentadores do exercício efetivo dos direitos humanos, por sua vez, servem como bases para a seguridade humana, bem como para o desenvolvimento econômico. ${ }^{3}$ Dentro deste recorte, melhorias no delineamento e execução dos direitos comuns, coletivos e privados à propriedade são condições essenciais para o progresso econômico em sociedades livres e abertas. ${ }^{4}$

${ }^{1}$ Disponível em:

$<$ http://www.ohchr.org/EN/ProfessionalInterest/Pages/CoreInstruments.aspx $>$. Acesso em: 12 de fevereiro de 2018. Cf. BUSCAGLIA, Edgardo. Legal and Economic Development: The Missing Links. Journal of Interamerican Studies and World Affairs, Vol. 35, 4, 1994; e BUSCAGLIA, Edgardo. Introduction to law and economics of development. In: Edgardo Buscaglia; William Ratliff; Robert Cooter (eds.). The Law and Economics of Development. Greenwich, CT: JAI Press, 1997.

${ }^{2}$ Cf. BUSCAGLIA, Edgardo. Institutional Factors Determining the Gap between Laws in the Books versus Laws in Action: An Analytical Framework for Improving Judicial Effectiveness. In: David Linnan (ed.). Legitimacy, Legal Development and Change:

Law and Modernization Reconsidered. London: Routledge, 2016.

${ }^{3}$ Cf. ACEMOGLU, Daron; ROBINSON, James A. Why Nations Fail: the origins of power, prosperity, and poverty. New York, NY: Crown Publishers, 2012; e HAYEK, Friedrich. Law, Legislation and Liberty, Vol. 1: Rules and Order. Chicago, IL: Chicago University Press, 1973.

${ }^{4}$ Cf. BUSCAGLIA, Edgardo. Legal and Economic Development: The Missing Links. Journal of Interamerican Studies and World Affairs, Vol. 35, 4, 1994; BUSCAGLIA, Edgardo. An analysis of judicial corruption and its causes: an objective governing- 
Buscaglia e Buscaglia \& Stephan demonstraram as razões pelas quais a oferta e a demanda por mecanismos formais e judiciários para solução de conflitos e por métodos informais e alternativos de resolução de disputas (MARD) ${ }^{5}$ ocorrem dentro de zonas rurais em 16 países. ${ }^{6} \mathrm{~A}$ análise fornecida a seguir realçará os fatores econômicos e jurídicos que levam à procura de MARD oferecidos por organizações criminosas transnacionais que buscam uma integração vertical dentro de atividades econômicas lícitas com o objetivo de incrementar seus mercados criminosos cada vez mais diversos em regiões e países específicos, nos quais estão presentes falhas de Estado.

A integração jurídico-econômica de organizações criminosas ocorre quando uma rede criminosa transnacional adquire, parcial ou completamente, a capacidade de gerar suas próprias matérias-primas para a produção de bens ou serviços ilegais, produzindo, transportando e distribuindo seus resultados finais, ao mesmo tempo em que controla sua comercialização nos setores atacadistas e varejistas.

Em pesquisa empírica comparativa internacional, restou comprovado que a corrupção política de alta cúpula tem sempre raízes em redes criminosas organizadas, compostas por funcionários públicos e/ou agentes privados não estatais dedicados a todos os tipos de crimes econômicos complexos, principalmente o tráfico de pessoas, drogas e armas, a falsificação, o contrabando, a extorsão, a fraude, o enriquecimento ilícito, os esquemas ilegais de financiamento de campanhas e a corrupção nas contratações públicas - por exemplo, fixando preços e manipulando ofertas com lavagem de dinheiro -, entre

based approach. International Review of Law and Economics, Vol. 21, 2, 2001; e HAYEK, Friedrich. Law, Legislation and Liberty, Vol. 1: Rules and Order. Chicago, IL: Chicago University Press, 1973.

${ }^{5}$ [N.T.] No original, o termo empregado é alternative dispute resolution mechanisms, frequentemente referido pelo acrônimo $A D R M$. Como se trata de matéria presente na literatura nacional, optou-se por utilizar, nesta versão para o português, a tradução "métodos alternativos de resolução de disputas", recorrendo-se ao acrônimo "MARD". ${ }^{6}$ Cf. BUSCAGLIA Edgardo. Investigating the links between Access to Justice and Governance Factors: An objective indicators' approach. Global Programme against Corruption Research and Scientific Series (United Nations Center for International Crime Prevention), No. CICP-13, 2001; e BUSCAGLIA, Edgardo; STEPHAN, Paul. An Empirical Assessment of the Impact of Formal versus Informal Dispute Resolution on Poverty: a Governance-Based Approach. International Review of Law \& Economics, Vol. 25, 1, 2005. 
outros. $^{7}$

A análise apresentada, neste estudo, demonstra que níveis mais elevados de integração vertical entre organizações criminosas e mercados lícitos vêm acompanhados de proteção política, esta obtida, principalmente, por meio do financiamento ilegal de campanhas eleitorais e contratações públicas ilegais em países que apresentam dificuldades em combater redes criminosas por meio de medidas confiscatórias cíveis e penais. Ao mesmo tempo, os vácuos institucionais do Estado incentivam segmentos sociais da população a demandarem o fornecimento de serviços sociais prestados por tais redes criminosas, beneficiando-se de esquemas mafiosos de proteção social. ${ }^{8}$

Em tese, as instituições responsáveis pela interpretação e aplicação das leis deveriam ser capazes de aplicar o necessário confisco civil e penal de ativos pertencentes a organizações criminosas transnacionais, a teor do disposto na Convenção das Nações Unidas contra o Crime Organizado Transnacional e na Convenção das Nações Unidas contra a Corrupção. ${ }^{9}$ Porém, na prática, quando os poderes executivo e judicial falham nessa aplicação, não se envolvendo no confisco de bens ${ }^{10}$ (quer em virtude de deficiências técnicas, corrupção política ou por conta de processos disfuncionais, elevando custos de transação e bloqueando o acesso à justiça), segue-se que a estrutura hierárquica das organizações criminosas prospera, tornando-se maior e publicamente mais notória,

${ }^{7}$ Cf. BUSCAGLIA, Edgardo. On best and not so good practices for addressing highlevel political corruption worldwide: an empirical assessment. In: Susan RoseAckerman; Tina Søreide (eds.). International Handbook on the Economics of Corruption, Volume Two. Northampton, MA: Edward Elgar Publishing, 2011. ${ }^{8}$ A corrupção de alta cúpula é definida como o uso de cargo público para beneficiar privadamente apadrinhados políticos e todos os tipos de altos funcionários eleitos. A análise de corrupção de alto escalão é abordada em BUSCAGLIA, Edgardo. On best and not so good practices for addressing high-level political corruption worldwide: an empirical assessment. In: Susan Rose-Ackerman; Tina Søreide (eds.). International Handbook on the Economics of Corruption, Volume Two. Northampton, MA: Edward Elgar Publishing, 2011.

${ }^{9}$ Cf. BUSCAGLIA, Edgardo. On best and not so good practices for addressing highlevel political corruption worldwide: an empirical assessment. In: Susan RoseAckerman; Tina Søreide (eds.). International Handbook on the Economics of Corruption, Volume Two. Northampton, MA: Edward Elgar Publishing, 2011. ${ }^{10} \mathrm{O}$ termo falha estatal será usado para descrever a incapacidade sistemática e/ou a falta de vontade de um Estado de fornecer respostas judiciais, como, por exemplo, a possibilidade de um órgão judicial determinar o confisco de ativos. 
alcançando as integrações verticais e horizontais de seu império, minimizando os custos de transação de futuros mercados ilegais vis-à-vis transações organizacionais internas. O trabalho teórico seminal de Williamson fornece os fundamentos para essa conclusão. ${ }^{11}$

O papel da informalidade no fornecimento de métodos alternativos de resolução de disputas (doravante, MARD), ora sob análise, vai ao encontro da fundamental pesquisa anterior de Buscaglia, de Buscaglia \& Ratliff e de Buscaglia \& van Dijk. ${ }^{12}$ Estendendo a análise anterior, dois tipos de MARD são analisados no presente estudo: o primeiro consiste em uma combinação de mediação e arbitragem oferecida por redes criminosas organizadas, a fim de preencher vácuos institucionais do

${ }^{11}$ Cf. WILLIAMSON, Oliver. The Economics of Organization: The Transaction Cost Approach. The American Journal of Sociology, Vol. 87, 3, 1981; e WILLIAMSON, Oliver. Transaction Costs Economics: An Introduction. Economics Discussion Papers, No. 2007-3, 2007. Disponível em: < $\underline{\text { http://www.economics- }}$ ejournal.org/economics/discussionpapers/2007-3/at download/file>. Acesso em: 12 de fevereiro de 2018.

${ }^{12}$ Cf. BUSCAGLIA, Edgardo. Legal and Economic Development: The Missing Links. Journal of Interamerican Studies and World Affairs, Vol. 35, 4, 1994; BUSCAGLIA, Edgardo. Introduction to law and economics of development. In: Edgardo Buscaglia; William Ratliff; Robert Cooter (eds.). The Law and Economics of Development. Greenwich, CT: JAI Press, 1997; BUSCAGLIA, Edgardo. An analysis of judicial corruption and its causes: an objective governing-based approach. International Review of Law and Economics, Vol. 21, 2, 2001; BUSCAGLIA Edgardo. Investigating the links between Access to Justice and Governance Factors: An objective indicators' approach. Global Programme against Corruption Research and Scientific Series (United Nations Center for International Crime Prevention), No. CICP-13, 2001; BUSCAGLIA, Edgardo. On best and not so good practices for addressing high-level political corruption worldwide: an empirical assessment. In: Susan Rose-Ackerman; Tina Søreide (eds.). International Handbook on the Economics of Corruption, Volume Two. Northampton, MA: Edward Elgar Publishing, 2011; BUSCAGLIA, Edgardo. Vacíos de Poder en Mexico. Ciudad de México, DF: Random House Mondadori, 2013; BUSCAGLIA, Edgardo. Dispute resolution mechanisms provided by violent non-state actors: An international comparative analysis of causes and consequences. In: Stefano Ruzza; Anja Jakobi; Charles Geisler (eds.). Non-State Challenges in a Re-Ordered World: The Jackals of Westphalia. London: Routledge, 2015; BUSCAGLIA, Edgardo; RATLIFF, William. War and Lack of Governance in Colombia: Narcos, Guerrillas and U.S. Policy. Stanford, CA: Hoover Institution Press, 2001; e BUSCAGLIA, Edgardo; VAN DIJK, Jan. Controlling Organized Crime and Corruption in the Public Sector. Forum on Crime and Society, Vol. 3, 1-2, 2003. 
Estado na prestação jurisdicional em ambientes sociais profundamente marcados pela cultura de fornecimento de todos os tipos de esquemas mafiosos de proteção a grupos sociais por organizações criminosas. Buscaglia demostra que, geralmente, as partes com acesso a MARD fornecidos por redes informais, na Colômbia ou no Congo, têm a oportunidade de chegar a uma autocomposição mediada por um representante da organização criminosa. ${ }^{13}$ Se um acordo não for alcançado, o mediador proferirá uma sentença arbitral pela imposição de uma resolução fundada em sanções sociais e, se necessário, violência. $\mathrm{O}$ segundo MARD mais típico é o tradicional mecanismo de resolução de litígios por órgãos de anciãos (por exemplo, os Jirgas no Afeganistão).

Buscaglia comprova que os MARD substituem de forma imperfeita a adjudicação oferecida pelo Estado. ${ }^{14}$ Sendo assim, a fim de serem capazes de operar de forma sustentável, esses MARD devem estabelecer ou manter legitimidade perante os segmentos mais economicamente marginalizados das populações que atendem. Buscaglia demonstra, ainda, que, dentro desses mesmos tipos de ambientes institucionais e sociais caracterizados por falhas jurídico-estatais em garantir o direito humano de acesso à justiça, há também uma ausência de resolução judicial de litígios relacionados a direitos de propriedade. ${ }^{15}$ Em suma, pesquisas anteriores mostraram que, em regiões onde há uma fraca proteção do direito formal de acesso à justiça, ocorre maior procura por MARD fornecidos por órgãos informais socialmente legitimados. A fim de expandir essa pesquisa anterior, pode-se agora tomar por hipótese, com base em observações empíricas mundiais, que as redes de organizações criminosas também estão envolvidas no fornecimento frequente de MARD como um quid pro quo pela proteção social. Com base em dados empíricos coletados por Buscaglia, também se poderia explicar

\footnotetext{
${ }^{13}$ Cf. BUSCAGLIA, Edgardo. Dispute resolution mechanisms provided by violent nonstate actors: An international comparative analysis of causes and consequences. In: Stefano Ruzza; Anja Jakobi; Charles Geisler (eds.). Non-State Challenges in a ReOrdered World: The Jackals of Westphalia. London: Routledge, 2015.

${ }^{14}$ Cf. BUSCAGLIA Edgardo. Investigating the links between Access to Justice and Governance Factors: An objective indicators' approach. Global Programme against Corruption Research and Scientific Series (United Nations Center for International Crime Prevention), No. CICP-13, 2001.

${ }^{15} \mathrm{Cf}$. BUSCAGLIA, Edgardo. Dispute resolution mechanisms provided by violent nonstate actors: An international comparative analysis of causes and consequences. In: Stefano Ruzza; Anja Jakobi; Charles Geisler (eds.). Non-State Challenges in a ReOrdered World: The Jackals of Westphalia. London: Routledge, 2015.
} 
porque a integração vertical das redes de crime organizado que fornecem MARD são tão frequentemente apoiadas pelo fornecimento de insumos econômicos, tais como mão-de-obra e terras, provenientes dos usuários destes MARD. ${ }^{16}$

Alguns mecanismos legais socialmente legitimados não constituem verdadeiros sistemas, mas sim uma série de estruturas baseadas no princípio da justiça restaurativa destinadas a compor litígios privados. $\mathrm{O}$ objetivo consiste em restabelecer a posição inicial da comunidade ou do indivíduo vitimado e, ao mesmo tempo, abordar e neutralizar a causa do imbróglio. Este princípio de justiça restaurativa está em nítido contraste com a justiça retributiva que se concentra em punir o autor de uma ofensa para compensar a sociedade. ${ }^{17}$

Em contrapartida, as decisões em MARD proferidas por agentes não estatais violentos são muitas vezes garantidas por um ou vários indivíduos dentro de grupos armados que oferecem um serviço mafioso de resolução de conflitos. As suas decisões são proferidas independentemente do consentimento da vítima e, em todos os casos, sem observância das garantias processuais (devido processo), exigido pelas convenções de direitos humanos das Nações Unidas. ${ }^{18}$ A matéria do litígio pode abranger aspectos políticos, econômicos, sociais, religiosos ou penais. Uma grande porcentagem dos casos resolvidos por estes mecanismos envolve conflitos comerciais e contratuais, reivindicações de herança ou propriedade, e ainda casos de crimes de furto, estupro, vandalismo ou mesmo homicídios. ${ }^{19}$ Estas decisões informais geralmente representam a principal ou a única saída para a resolução de litígios entre os segmentos mais marginalizados das populações de favelas urbanas e

${ }^{16}$ Cf. BUSCAGLIA, Edgardo. Dispute resolution mechanisms provided by violent nonstate actors: An international comparative analysis of causes and consequences. In: Stefano Ruzza; Anja Jakobi; Charles Geisler (eds.). Non-State Challenges in a ReOrdered World: The Jackals of Westphalia. London: Routledge, 2015.

${ }_{17}$ Cf. PEDROSO, João; TRINCÃO, Catarina. The (Re)birth of the Justice of the Peace: Democratic or Technocratic Justice Reform? The Experiences of Italy, Spain, Brazil and Portugal. Beyond Law, Vol. 19, 27, 2004.

${ }^{18}$ Estas convenções incluem a Carta das Nações Unidas, os dois Pactos Internacionais sobre os direitos políticos, civis, econômicos, sociais e culturais, e todos os outros catorze instrumentos jurídicos garantidores de uma ampla variedade de direitos humanos. Cf. as Convenções da ONU sobre direitos humanos em: $<$ http://www.ohchr.org/EN/ProfessionalInterest/Pages/CoreInstruments.aspx $>$. Acesso em: 12 de fevereiro de 2018.

${ }^{19}$ WOJKOWSKA, Ewa. Doing justice: How Informal Justice Systems can contribute. New York, NY: United Nations Development Programme, 2006. 
de localidades rurais. ${ }^{20}$ Por vezes, tais decisões são legitimadas pela comunidade envolvida, porém, isto não ocorre sempre.

Por outro lado, os mecanismos informais de resolução de conflitos podem coexistir com juízes, promotores, policiais ou governadores que direcionam casos complexos para os canais informais, a fim de aliviar seu acervo ou simplesmente evitar a reprovação social de suas decisões ruins. ${ }^{21}$

Em razão do fato de os segmentos da população mais vulneráveis social, econômica e/ou etnicamente serem marginalizados pelo sistema de justiça formal, sendo barrados de acessar mecanismos de mediação e arbitragem fornecidos por tribunais, esses se inclinam a demandarem tais serviços a agentes informais não estatais. ${ }^{22}$ Dentro desses segmentos privados das populações que enfrentam contextos de disfunções judiciais e falta de confiança pública, muitas redes criminosas organizadas oferecem MARD aos tutelados pelo Estado. ${ }^{23}$ Essas descobertas sobre a

${ }^{20}$ Cf. JACOBY, Sidney. Access to Justice. The American Journal of Comparative Law, Vol. 29, 3, 1981. Resenha de: CAPPELLETTI, Mauro; GARTH, Bryant; WEISNER, John; KOCH, Klaus-Friedrich. Access to Justice. Milan: Giuffrè, 1979; e BUSCAGLIA, Edgardo. An analysis of judicial corruption and its causes: an objective governingbased approach. International Review of Law and Economics, Vol. 21, 2, 2001. ${ }^{21}$ Cf. BIROL, Aline Pedra Jorge; DAL RI, JR., Arno. The Role of Organized Crime in Informal Justice Systems. Uluslararası Güvenlik ve Terörizm Dergisi, Vol. 2, 1, 2011; e SUNG, Hung-En. State Failure, Economic Failure, and Predatory Organized Crime: A Comparative Analysis. Journal of Research in Crime and Delinquency, Vol. 41, 2, 2004.

${ }^{22}$ Cf. SANTOS, Boaventura de Souza. The Law of the Oppressed: the Construction and Reproduction of Legality in Pasárgada. Law \& Society Review, Vol. 12, 1, 1977; BUSCAGLIA, Edgardo. An analysis of judicial corruption and its causes: an objective governing-based approach. International Review of Law and Economics, Vol. 21, 2, 2001; SUNG, Hung-En. State Failure, Economic Failure, and Predatory Organized Crime: A Comparative Analysis. Journal of Research in Crime and Delinquency, Vol. 41, 2, 2004; BIROL, Aline Pedra Jorge; DAL RI, JR., Arno. The Role of Organized Crime in Informal Justice Systems. Uluslararası Güvenlik ve Terörizm Dergisi, Vol. 2, 1, 2011; e JAMIESON, Neil, MOI, Stephen, \& CHEROT, Jason. Acting outside the box: The emerging dispute resolution centres developing innovative ways to attract business. Legal Week, 07 jun. 2012. Disponível em:

$<$ http://www.legalweek.com/sites/legalweek/2012/06/07/acting-outside-the-box-theemerging-dispute-resolution-centres-developing-innovative-ways-to-attractbusiness/>. Acesso em: 12 de fevereiro de 2018.

${ }^{23}$ Cf. BIROL, Aline Pedra Jorge; DAL RI, JR., Arno. The Role of Organized Crime in Informal Justice Systems. Uluslararası Güvenlik ve Terörizm Dergisi, Vol. 2, 1, 2011; 
demanda de resolução alternativa de conflitos longe do jugo estatal podem ser enquadradas, em parte, na pesquisa de teoria dos jogos sobre confiança e sinalização desenvolvida por Gambetta. ${ }^{24}$

Pesquisa anterior relacionada a essa mesma análise defendeu a premissa de que existem altos custos de transação para aqueles que buscam a resolução de conflitos em Estados com fracos mecanismos de governança, os quais sofrem com altos níveis de corrupção (gerando pressões indevidas para a utilização do sistema judicial em benefício privado) com complexidades processuais. ${ }^{25}$ Isso pode explicar porque mecanismos informais alternativos de resolução de conflitos são procurados por segmentos da população com baixo poder aquisitivo e por esses segmentos empresariais que estão dispostos a pagar um pesado preço pela arbitragem privada em mercados tecnológicos altamente sofisticados. Além disso, a alta demanda por mecanismos alternativos privados de resolução de conflitos ocorre predominante por litigantes em ambientes com lacunas institucionais. Em outras palavras, elevados custos de transação emergem de resolução de litígios nos países devido a vácuos institucionais (ou seja, ausência de instituições necessárias) ou ligadas a falhas de corrupção das instituições judiciais. Outro indicador de tal demanda é a alta incidência de mecanismos privados de resolução de conflitos. Estas soluções são desejáveis quando, por exemplo, existem imbróglios comerciais tecnicamente complexos que não colocam em risco direitos públicos e coletivos, e quando inexiste o componente de bem

PEDROSO, João; TRINCÃO, Catarina. The (Re)birth of the Justice of the Peace: Democratic or Technocratic Justice Reform? The Experiences of Italy, Spain, Brazil and Portugal. Beyond Law, Vol. 19, 27, 2004; SANTOS, Boaventura de Souza. The Law of the Oppressed: the Construction and Reproduction of Legality in Pasárgada. Law \& Society Review, Vol. 12, 1, 1977; SCHÄRF, Wilfried. Non-State Justice Systems in Southern Africa: How Should Governments Respond? In: Workshop on Working with Non-State Justice Systems. Paper apresentado. London: University of Bermingham,

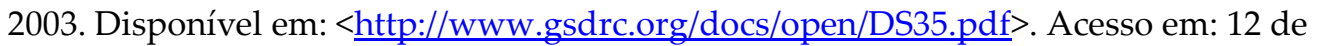
fevereiro de 2018; e WOJKOWSKA, Ewa. Doing justice: How Informal Justice Systems can contribute. New York, NY: United Nations Development Programme, 2006.

${ }^{24}$ GAMBETTA, Diego. The Sicilian Mafia: The Business of Private Protection. Cambridge, MA: Harvard University Press, 1993.

${ }^{25}$ Cf. BUSCAGLIA, Edgardo. Judicial Corruption in Developing Countries: Its Causes and Economic Consequences. Stanford, CA: Hoover Institution Press, 1999; e BUSCAGLIA, Edgardo; STEPHAN, Paul. An Empirical Assessment of the Impact of Formal versus Informal Dispute Resolution on Poverty: a Governance-Based Approach. International Review of Law \& Economics, Vol. 25, 1, 2005. 
público em uma resolução arbitral. Comparações de 16 países demonstram que em disputas envolvendo condutas criminosas ou direitos civis, políticos, econômicos, sociais e culturais fundamentais (ou seja, nas quais os indivíduos buscam soluções com um forte componente de bem público), os litigantes consideram os mecanismos informais como a terceira opção após a mediação oficial e direta patrocinada pelo Estado (primeira melhor) e as decisões judiciais oficiais (como a segunda melhor). ${ }^{26}$ Ao mesmo tempo, eles buscam a tutela estatal para resolver conflitos acerca de direitos de propriedade, quando possível, de modo a contar com os documentos oficiais capazes de comprovar seus direitos em caso de problemas futuros. Em outras palavras, as consequências que emergem das resoluções informais de conflitos somente fornecem uma solução jurídica socialmente aceita em casos específicos, nos quais um agente não estatal atua e possui legitimidade social para tanto.

Em razão do acima exposto, este estudo procura explicar a análise de custo-benefício por detrás de maiores ou menores frequências no recurso à resolução de disputa informal fornecida por grupos armados não estatais em ambientes em que o direito humano ao acesso justiça oficial é precário ou, na prática, ausente. Grupos armados não estatais fornecedores de MARD esperam em quid pro quo, ou, em outras palavras, como troca pelos serviços de MARD, que as comunidades forçosamente forneçam bens e/ou mão-de-obra para a organização criminosa responsável pela rede armada de solução de conflitos. Esse suporte ao usuário pode incluir recursos humanos, infraestrutura logística e proteção social contra grupos rivais (às vezes, o próprio Estado) em quid pro quo. ${ }^{27}$

Muitos doutrinadores avaliaram o acesso a mecanismos informais e públicos de resolução de conflitos oferecidos por agentes não estatais. Em oposição a iniciativas anteriores, no entanto, este estudo avalia o acesso a mecanismos públicos e privados de resolução de conflitos em ambientes nos quais as redes criminosas organizadas prevalecem e buscam apoio econômico para sua expansão dentro de domínios legais e ilegais. Com base em relatos anteriores do crime organizado no fornecimento de bens

${ }^{26}$ Cf. BUSCAGLIA, Edgardo; STEPHAN, Paul. An Empirical Assessment of the Impact of Formal versus Informal Dispute Resolution on Poverty: a Governance-Based

Approach. International Review of Law \& Economics, Vol. 25, 1, 2005.

${ }^{27}$ Cf. BUSCAGLIA Edgardo. Investigating the links between Access to Justice and Governance Factors: An objective indicators' approach. Global Programme against Corruption Research and Scientific Series (United Nations Center for International Crime Prevention), No. CICP-13, 2001; e BUSCAGLIA, Edgardo. Vacíos de Poder en Mexico. Ciudad de México, DF: Random House Mondadori, 2013. 
e serviços para comunidades vulneráveis ${ }^{28}$, este estudo fornece uma interpretação conceitual de como as associações criminosas expandem seus serviços de resolução de conflitos e aponta para o paradoxo de Estados fracos dependerem do gerenciamento de conflitos não estatais a tal ponto que se esquivam de reformas judiciais muito necessárias. Por conseguinte, este estudo irá fornecer dados objetivo não perceptíveis demostrando a associação entre três variáveis:

(1) A falha do Poder Judiciário na prestação jurisdicional para os segmentos mais vulneráveis da população e na tomada de medidas confiscatórias contra ativos provenientes de crimes;

(2) O consequente aumento da demanda social por mecanismos alternativos de resolução de conflitos fornecidos por redes armadas do crime organizado; e

(3) $\mathrm{O}$ consequente aumento da integração vertical dessas mesmas redes criminosas na esfera jurídica para dar suporte a uma maior diversificação de mercados ilícitos (ou seja, produção de drogas, tráfico de armas e pessoas, falsificações, etc.), todos acompanhados por corrupção no financiamento de campanhas eleitorais e nas contratações públicas como canais de proteção política.

Esses três conjuntos de dados serão testados por meio de uma hipótese segundo a qual as melhorias no desempenho judicial relacionadas ao aprimoramento do acesso aos tribunais nas regiões em que as redes criminosas fornecem MARD, combinadas com ordens judiciais de confisco de ativos mais frequentes contra essas mesmas redes criminosas, reduzirão a escala e o escopo do crime organizado em termos de diminuição da sua integração vertical na economia legal e redução da corrupção política nos domínios das eleições e dos contratos públicos. Em Buscaglia, estas duas esferas representam empiricamente os tipos mais frequentes de corrupção política em todo o mundo. ${ }^{29}$ Se essa hipótese for comprovada, então, em seguida, poderá se depreender que melhorias no exercício dos direitos de acesso à justiça via instituições penais juntamente com aplicações mais frequente de sanções de confisco terão

${ }^{28}$ Cf. MILHAUPT, Curtis; WEST, Mark. The Dark Side of Private Ordering: An Institutional and Empirical Analysis of Organized Crime. University of Chicago Law Review, Vol. 67, 1, 2000.

${ }^{29}$ Cf. BUSCAGLIA, Edgardo. On best and not so good practices for addressing highlevel political corruption worldwide: an empirical assessment. In: Susan RoseAckerman; Tina Søreide (eds.). International Handbook on the Economics of Corruption, Volume Two. Northampton, MA: Edward Elgar Publishing, 2011. 
um impacto direto na redução da escala e do escopo do crime organizado e da corrupção política.

\section{ANÁLISE JURIMÉTRICA INTERNACIONAL COMPARADA NA EFICIÊNCIA ALOCATIVA DOS SISTEMAS JUDICIAIS}

Em todo o mundo, muitos sistemas judiciais sofrem de uma crônica falta de qualidade, transparência e imparcialidade em suas decisões devido ao alto nível de corrupção política endêmica, a qual exerce pressões sobre o sistema judicial, combinada com a falta de capacidade técnica institucional. ${ }^{30}$ Os elementos básicos de um sistema judicial eficaz podem restar ausentes, dentre eles: procedimentos e resultados previsíveis; acessibilidade por todos os segmentos da população, independentemente de renda e nível educacional, a fim de cumprir com padrões e normas de direitos humanos; acervos processuais suportáveis, com tempo razoável para deliberação; e soluções adequadas fornecidas pelos tribunais. Nos casos em que todos ou alguns destes quatro elementos estão ausentes, perde-se confiança na administração da justiça, especialmente por parte de pequenas empresas privadas e indivíduos de baixa renda. ${ }^{31}$ Como resultado, esses segmentos de baixa renda da população envolvidas em um litígio tendem a procurar outros mecanismos, ou simplesmente recorrer à justiça privada, por vezes utilizando a violência em suas mais variadas formas, como em linchamentos. Nesse contexto, a mediação ou a arbitragem informal pode oferecer uma eficiente válvula de segurança com vantagens para determinados tipos de litígio. No entanto, em muitos outros tipos de contendas envolvendo a violação dos direitos fundamentais culturais, sociais, políticos, civis e de acesso à justiça, os remédios podem restar inobservados em países com sistemas judiciais incipientes. Estes déficits na provisão de mecanismos de resolução de litígios prejudicam a legitimidade do Estado e sobrecarregam desproporcionalmente os

${ }^{30}$ Cf. BUSCAGLIA, Edgardo. Judicial Corruption in Developing Countries: Its Causes and Economic Consequences. Stanford, CA: Hoover Institution Press, 1999.

${ }^{31}$ Cf. BUSCAGLIA, Edgardo. An analysis of judicial corruption and its causes: an objective governing-based approach. International Review of Law and Economics, Vol. 21, 2, 2001; e BUSCAGLIA Edgardo. Investigating the links between Access to Justice and Governance Factors: An objective indicators' approach. Global Programme against Corruption Research and Scientific Series (United Nations Center for International Crime Prevention), No. CICP-13, 2001. 
segmentos mais pobres da população. ${ }^{32}$

A fim de resolver estas falhas com base em uma comparação jurimétrica internacional, dados jurimétricos objetivos são necessários, não apenas levantamentos sobre a percepção dos jurisdicionados. Para atender a essa necessidade, os dados descritivos encontrados na Tabela 1 a seguir fornecem evidência jurimétrica de aumento ou diminuição da eficiência na alocação de recursos orçamentários para a oferta de serviços judiciais, abordando uma amostra representativa de resoluções envolvendo litígios de propriedade privada e casos relacionados a organizações criminosas dentro de uma região específica em 20 países onde esses mesmas organizações criminosas ofertaram mecanismos de resolução de conflitos durante o período de 2004 a 2014.

A eficiência na alocação de recursos é extraída a partir de relações de entrada/saída. Indicadores de entrada judicial são medidos na Tabela 1 por meio da média decenal das séries que medem alterações percentuais anuais em alocações de orçamento para infraestrutura de tribunais físicos, treinamento judicial, tecnologia e salários com a inclusão de benefícios. Por seu turno, os indicadores de saída são fornecidos nas duas últimas colunas que medem uma série temporal de variações percentuais médias decenais nas taxas de solução $0^{33}$, entendidas como mudanças percentuais anuais no número de processos envolvendo a atuação do crime organizado no financiamento ilícito de campanhas políticas e/ou na corrupção em contratações públicas que são julgados anualmente em relação a casos pendentes de decisão. A corrupção política ligada a contratações públicas envolvem casos de tentativa de fraude eleitoral, fixação de preços e conluio envolvendo contratos de infraestruturas e bens públicos. A última coluna mede as mudanças percentuais médias decenais na frequência de violações judiciais das legislações materiais e processuais penais encontradas por meio de revisão técnica de uma amostra anual de processos envolvendo a atuação de organizações criminosas no financiamento de campanhas políticas e/ou na corrupção em contratações públicas, em cada uma das regiões de 20 países onde MARD foram ofertados por essas mesmas redes de crime organizado para segmentos marginalizados da população. Um sistema judiciário será classificado como eficiente na medida em que os aumentos na porcentagem média anual das dotações orçamentária estiverem

${ }^{32}$ Cf. BUSCAGLIA Edgardo. Investigating the links between Access to Justice and Governance Factors: An objective indicators' approach. Global Programme against Corruption Research and Scientific Series (United Nations Center for International Crime Prevention), No. CICP-13, 2001.

${ }^{33}$ [N.T.] No original, foi empregada a expressão clearence rate. 
associados a um aumento mais que proporcional na porcentagem média anual das taxas de solução e na qualidade das resoluções judiciais (ou seja, na redução percentual anual de erros judiciais). Portanto, em nossa descrição jurimétrica e análise encontradas na Tabela 1 podemos medir a quantidade e a qualidade da prestação dos serviços judiciais.

Pode-se extrair da Tabela 1 abaixo que a Argentina experimentou uma média de crescimento médio decenal de $6 \%$ nas alocações orçamentárias dedicadas à infraestrutura e um aumento médio decenal de $3 \%$ em seu orçamento dedicado à tecnologia judicial, enquanto suas rubricas orçamentárias dedicadas ao treinamento de pessoal diminuíram $2 \%$ no mesmo intervalo de tempo. Por seu turno, o aumento salarial médio no período foi de $67 \%$. Simultaneamente, os índices de resolução de conflitos da Argentina sofreram uma diminuição média decenal (isto é, a proporção entre a solução de casos e a existência de casos pendentes, no que diz respeito ao confisco de ativos criminais, diminuiu $18 \%$, com o consequente aumento de atrasos) e os erros encontrados nas decisões judiciais relativas à perda de ativos criminais aumentaram 23\% entre 2004 e 2014 (em outras palavras, em média, os juízes e promotores que tratam do confisco de ativos ilícitos do crime organizado cometeram $23 \%$ mais erros processuais e materiais em 2014 em relação a 2004, reduzindo assim a qualidade de suas decisões judiciais). Isso significa simplesmente que, apesar de aumentos percentuais nos recursos orçamentários dedicados aos salários judiciais e à tecnologia, o setor judicial argentino está deixando de liberar de seus acervos casos envolvendo o crime organizado (considerando casos pendentes) e está presenciando menor qualidade em suas decisões abordando o confisco de ativos de redes criminosas. Portanto, a Argentina pode ser classificada como ineficiente em termos de desempenho judicial.

O mesmo padrão de ineficiência pode ser observado no restante dos países incluídos na amostra incluída na Tabela 1 abaixo, com exceção do Chile, Colômbia e, em menor medida, Botsuana e Uruguai. Mais especificamente, o Chile e a Colômbia, experimentaram aumentos percentuais significativos em seus recursos orçamentários (como parte de suas reformas judiciais para a instalação de um sistema jurídico processual baseado na oralidade). Esses aumentos nas rubricas orçamentárias foram destinados ao aprimoramento tecnológico dos tribunais, à formação dos servidores judiciais, à infraestrutura e, em menor medida ao incremento de salários. No domínio da produção judicial do Chile e da Colômbia, a proporção dos casos encerrados para pendentes (ou seja, as taxas de solução) aumentou 132\% e a proporção de decisões amostradas com erros significativos diminuiu 58\% no Chile, enquanto, na Colômbia, a proporção de casos encerrados para os casos 
pendentes aumentou $97 \%$ (em grande parte por meio do uso de mecanismos alternativos de resolução de litígios) e a proporção de decisões amostradas com erros significativos (ou seja, qualidade judicial) diminuiu 27\% (ou seja, uma média de $27 \%$ menos de erros judiciais em 2014 em comparação com 2004), dando assim à Colômbia uma melhoria significativa em sua qualidade de sentenças judiciais. Por isso, o Chile e a Colômbia são os dois únicos países da nossa amostra que demonstram maior eficiência judicial, considerando a quantidade (percentual de aumento nas taxas de solução) e judicial (aumento percentual na proporção de processos de casos amostrados sem erros significativos que alteraram o curso das decisões em confisco de ativos da criminalidade organizada). Além disso, Botsuana e Uruguai também mostram indicadores de eficiência. $\mathrm{O}$ restante dos países, contudo, apresenta ineficiências ligadas aos aumentos de alocações orçamentárias que acompanham a diminuição da quantidade de casos, juntamente com a diminuição da qualidade das decisões judiciais. Finalmente, é preciso ter em conta que - por definição - uma diminuição nas frequências de erros judiciais em processos de confisco de ativos prejudicará a capacidade do crime organizado de alcançar a integração vertical de seus negócios lícitos. Essa ligação entre a integração vertical das redes criminosas dentro da economia legal e a eficiência judicial no confisco de bens de origem criminosa será explorada e testada abaixo.

Em suma, a análise jurimétrica na Tabela 1 indica associações positivas entre o percentual de alteração no orçamento para tecnologia, infraestrutura, formação e salários, de um lado, e as mudanças percentuais nos indicadores de quantidade e qualidade das decisões judiciais de outro. Nesse contexto, os únicos sistemas judiciais que mostram melhorias eficientes na qualidade do confisco judicial de ativos são Botsuana, com uma queda de $8 \%$ nos erros judiciais encontrados através do exame de casos de crime organizado, Chile, com uma queda de $58 \%$ erros judiciais, Colômbia, com uma queda de $27 \%$ nos erros judiciais nos mesmos tipos de casos envolvendo perda de ativos, e, finalmente, Uruguai, com uma queda de $12 \%$ nos erros. Conforme observa-se na Tabela 1, nesses mesmos quatro países ocorreram aumentos nas taxas de solução (isto é, casos de crime organizado envolvendo confisco de ativos com corrupção política em financiamento de campanhas eleitorais e contratos públicos estão sendo descartados a um ritmo mais rápido do que os casos pendentes). Em síntese, esses quatro países exibem eficiência de alocação judicial, mostrando aumentos percentuais nas dotações orçamentárias ligadas a aumentos mais do que proporcionais nos resultados judiciais (ou seja, em termos de aumentos percentuais anuais nas taxas de solução e de aumentos percentuais anuais na qualidade das resoluções judiciais). 
É preciso ter em conta que, na última coluna da Tabela 1, que mede a qualidade judicial, nossas equipes de revisão de processos mediram os erros dos juízes e promotores no atendimento dos direitos das vítimas do crime organizado de acesso à justiça, fundados em convenções internacionais de direitos humanos, ratificadas pelos 20 países amostrados, e também em leis processuais e materiais de cada país. Como resultado, os indicadores de erros judiciais medidos na última coluna da Tabela 1 abaixo incluem abusos de discrição judicial que envolvem violações dos direitos humanos das vítimas do crime organizado. Por exemplo, um relatório do Parlamento Europeu mostra que a Itália (entre outros Estados-Membros da União Europeia) requer que o sistema judicial indenize e conceda todo tipo de apoio às vítimas de crime organizado por meio da realocação de recursos obtidos do confisco de ativos de sanções penais para as redes da sociedade civil encarregadas de apoiar as vítimas de crime organizado. ${ }^{34} \mathrm{~A}$ este respeito, o reforço da eficiência judicial implica o reforço dos direitos humanos das vítimas.

${ }^{34}$ Lei 109/96, artigo 65(1). Cf. EUROPEAN PARLIAMENT. The Need for New EU Legislation Allowing the Assets Confiscated from Criminal Organizations to be Used for Civil Society and in Particular for Social Purposes. Brussels: European Parliament, 2012. Disponível em:

$<$ http://www.europarl.europa.eu/document/activities/cont/201206/20120627ATT47783/ 20120627ATT47783EN.pdf>. Acesso em: 12 de fevereiro de 2018. 
Tabela 1 - Variações percentuais anuais nas variáveis relacionadas à oferta que afetam a qualidade e a quantidade de serviços judiciais (2004-2014) ${ }^{35}$

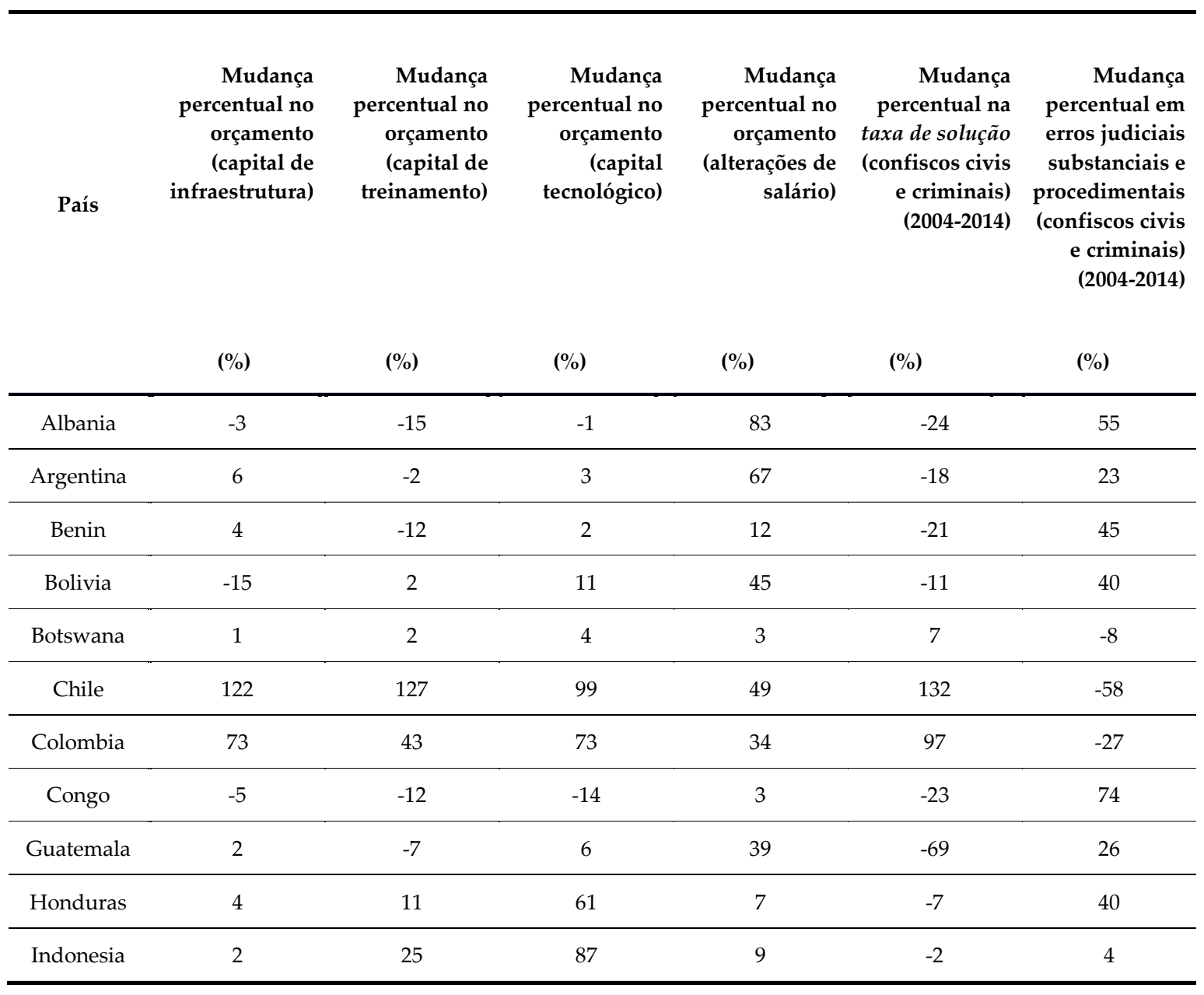

${ }^{35}$ As estatísticas acima foram arredondadas para cima. Todos os indicadores são dados primários desenvolvidos pelo autor e por equipes de campo em 20 países, com base em variações percentuais médias nas alocações orçamentárias (em termos reais, descontada a inflação, considerando preços de 1998) aprovadas pelos órgãos legislativos. Os dados sobre as taxas de solução são baseados em dados judiciais específicos extraídos das bases de dados dos tribunais em matéria de confisco penal e civil de ativos, entre 2004 e 2014. 
Independentemente das tradições sociais ou jurídicas, a incapacidade de um poder judiciário fraco de satisfazer o imperativo direito humano de acesso à justiça é um dos déficits de reformas judiciais mais desafiadores dos direitos humanos em todo o mundo. ${ }^{36}$ Por exemplo, no México, a cada 100 crimes cometidos organizadamente, em média, apenas um é objeto de qualquer tipo de medida judicial. ${ }^{37}$ Já no Afeganistão mais de $90 \%$ dos casos civis e criminais são escoados para sistemas informais de resolução de conflitos..$^{38}$ Além disso, em sistemas judiciários fracos, nomeações e promoções são baseadas no clientelismo ligado à corrupção política, o que ocorre juntamente com a falta de um modelo eficaz para avaliar o caráter psicológico e a aptidão dos candidatos para o cargo de juiz. Isso contribui para o fraco desempenho judicial, conforme mensurado na Tabela 1 acima, apesar de enormes somas de dinheiro público serem gastas em salários mais elevados na maioria dos países..$^{39}$ Poderia ser argumentado que o fornecimento da prestação jurisdicional e os incentivos de desempenho enfrentados por juízes, funcionários judiciais, policiais e serviços de promotoria dependem muito dos controles existentes para prevenir a corrupção política e judicial. Em última análise, a falta de instituições de governança (ou até mesmo a existência de lacunas estatais) sob a forma de completa ausência de controles judicial, administrativo, econômico e social a serem aplicados ao financiamento de campanhas políticas e contratos públicos estão no cerne da problemática envolvendo o crime organizado e os baixos índices de desenvolvimento humano em muitos países. Juízes mal treinados em um sistema legal sobrecarregado estão suscetíveis a serem alvos de práticas de corrupção por associações criminosas de políticos e empresários, criando assim um ambiente em que o Estado de Direito não pode ser garantido. Por exemplo, o uso da comunicação ex parte (reuniões separadas entre um poderoso litigante e um juiz sem a outra parte presente) é uma prática padrão no Afeganistão, na Indonésia, no México

${ }^{36}$ Cf. BUSCAGLIA, Edgardo; DAKOLIAS, Maria; RATLIFF, William. Judicial Reform in Latin America: a Framework for National Development. Stanford, CA: Hoover Institution Press, 1995.

${ }^{37}$ Cf. GONZÁLEZ RUIZ, Samuel; MENDIETA JIMÉNEZ, Ernesto; BUSCAGLIA, Edgardo; MORENO HERNANDEZ, Moisés. El Sistema de Justicia Penal y su

Reforma: Teoría y Práctica. $2^{\underline{a}}$ ed. Ciudad de México: Fontamara, 2006.

${ }^{38}$ Cf. COBURN, Noah; DEMPSEY, John. Informal dispute resolution in Afghanistan. United States Institute of Peace, Special Report No. 247, 2010.

${ }^{39}$ Cf. BUSCAGLIA, Edgardo; DAKOLIAS, Maria; RATLIFF, William. Judicial Reform in Latin America: a Framework for National Development. Stanford, CA: Hoover Institution Press, 1995. 
e no Zimbábue. É um exemplo de prática legal que expulsa os usuários do sistema judicial, independentemente do desejo ou da capacidade de subornar - e isso mesmo no domínio de resolução de disputas tradicional ou penal. No Afeganistão, no México e no Paraguai, há casos decididos em reuniões ex parte, nas quais os advogados dos litigantes procuram juízes e seus assessores para redigir as minutas das decisões judiciais. ${ }^{40}$ Estes fatores também, em parte, explicam o mau desempenho na Tabela 1 acima.

Esses problemas aumentam o custo e o risco de deter os direitos de propriedade entre empreendedores de pequeno porte ou entre unidades de agricultura doméstica. Isto, por sua vez, reduz o potencial dos fluxos de investimentos em direção à terra e ao capital humano. Ao mesmo tempo, a obstrução do acesso à justiça favorece a dependência de mecanismos informais não estatais frequentemente fornecidos por associações criminosas para resolver litígios por meio de justiça popular em troca de disponibilização de terras para o cultivo de drogas. Ou resulta na oferta quid pro quo de mão-de-obra para o crime organizado por jovens membros das famílias rurais, constituindo, assim, um canal para que o crime organizado capture e controle o tecido social. ${ }^{41}$

Além disso, quando as famílias rurais não confiam que a imissão e outros direitos de propriedade serão resguardados por canais formais judiciais ou administrativos, surgem obstáculos à formalização de títulos de propriedade em órgãos notariais rurais, bloqueando o acesso a crédito formal e o fluxo futuro de investimentos em terra e capital humano. ${ }^{42} \mathrm{~A}$ esse respeito, pesquisas empíricas foram desenvolvidas desde o final da década de 1980 a fim de fornecer amplos argumentos para defender o efeito perverso de setores públicos imporem altos custos de transação sobre os indivíduos. Em suma, autores como De Soto e North explicam

${ }^{40}$ Cf. BUSCAGLIA, Edgardo. Judicial Corruption in Developing Countries: Its Causes and Economic Consequences. Stanford, CA: Hoover Institution Press, 1999. ${ }^{41}$ Para um relato deste pernicioso processo na Colômbia, ver BUSCAGLIA, Edgardo; RATLIFF, William. War and Lack of Governance in Colombia: Narcos, Guerrillas and U.S. Policy. Stanford, CA: Hoover Institution Press, 2001; para o Japão e a Rússia, cf. MILHAUPT, Curtis; WEST, Mark. The Dark Side of Private Ordering: An Institutional and Empirical Analysis of Organized Crime. University of Chicago Law Review, Vol. 67, 1, 2000.

${ }^{42}$ Cf. DE SOTO, Hernando. The Other Path: The Invisible Revolution in the Third World. New York, NY: Harper \& Row, 1989; DE SOTO, Hernando. The Mystery of Capital: Why Capitalism Triumphs in the West and Fails Everywhere Else. New York, NY: Basic Books, 2000; e NORTH, Douglass. Institutions, Institutional Change and Economic Performance. Cambridge, MA: Cambridge University Press, 1990. 
como as complexidades processuais do Estado e a corrupção adicionam custos de transação ao exercício formal de direitos de propriedade..$^{43}$ No entanto, esses mesmos autores e outros, seguindo a abordagem da análise econômica do direito, não aprofundam quais espécies desejáveis ou indesejáveis de resolução informal de conflitos podem surgir como resultado, especialmente, quando estes MARD são oferecidos por grupos criminosos armados em meio a vácuos estatais. A análise proposta preenche essa lacuna de pesquisa.

\section{UMA ANÁLISE COMPARATIVA DE PROCESSOS JUDICIAIS E FATORES SOCIAIS LIGADOS À PROCURA POR MARD}

Reitera-se que esta análise visa demonstrar que o maior grau de integração vertical das organizações criminosas em atividades lícitas (grau, por exemplo, no qual uma organização criminosa adquire (1) a capacidade econômica de gerar suas próprias matérias-primas, tais como a pasta de coca; (2) produzir o bem ou serviço a ser traficado, como a cocaína pura; (3) transportar o bem ou serviço a ser traficado, por exemplo, por meio de navios próprios; (4) controlar a rede de distribuição do bem ou serviço; (5) controlar o comércio atacadista; e (6) controlar o comércio varejista) ocorre mais frequentemente nos países em que falhas estatais mais agudas impedem o desmantelamento legal e judicial de organizações criminosas por meio do confisco de ativos nos domínios dos contratos públicos e das campanhas eleitorais. Note-se que todos os vinte países amostrados neste estudo assinaram e ratificaram a Convenção das Nações Unidas contra o Crime Organizado, seus protocolos e a Convenção das Nações Unidas contra a Corrupção, as quais exigem o desenvolvimento de capacidades judiciais de confisco e recuperação de ativos. Portanto, nossa análise empírica também aborda a avaliação de cada país no cumprimento de suas obrigações convencionais previstas nos instrumentos depositados perante as Nações Unidas. ${ }^{44}$

${ }^{43}$ Cf. DE SOTO, Hernando. The Other Path: The Invisible Revolution in the Third

World. New York, NY: Harper \& Row, 1989; e NORTH, Douglass. Institutions,

Institutional Change and Economic Performance. Cambridge, MA: Cambridge

University Press, 1990.

${ }^{44}$ Cf. Artigos, 2º , 6⿳⺈, 12 e 13 da Convenção das Nações Unidas contra o Crime

Organizado Transnacional. Disponível em:

$<$ http://www.unodc.org/documents/treaties/UNTOC/Publications/TOC $\% 20$ Conventio

n/TOCebook-e.pdf $>$. Acesso em: 15 de fevereiro de 2018. 
Nesse contexto, esta pesquisa expande conclusões anteriores, fornecendo evidências de que uma maior diversificação de crimes cometidos por redes transnacionais protegidas pela corrupção da alta cúpula política será apoiada por um maior grau de integração vertical dentro de mercados lícitos ligados à corrupção política e outros tipos de atividades criminosas.

Com base nos fundamentos teóricos de Oliver Williamson, entendese que o grau mais diversificado de integração das atividades econômicas legais realizadas por organizações criminosas visa atender ao objetivo de reduzir os custos de transação ligados à frequência, especificidade, incerteza, racionalidade limitada e oportunidade do comportamento em transações de mercado em ambientes econômicos em que outras organizações criminosas também competem por esses mesmos mercados legais para apoiar a expansão de suas próprias atividades criminosas. ${ }^{45}$

Neste cenário, Buscaglia comprovou que as violações sistêmicas do direito de acesso à justiça por segmentos marginalizados social, econômica ou etnicamente da população se traduzem em uma maior disponibilização de MARD por estruturas tradicionais de governança informal, tais como assembleias de notáveis ou anciãos. ${ }^{46}$ Em suma, com base na literatura já referenciada, pode-se supor que as falhas próprias do sistema judicial incentivam buscas mais frequentes a MARD que deveriam ser fornecidas por fontes oficiais, mas que passam a ser fornecidas também por grupos criminosos que procuram uma maior diversificação dos seus mercados ilícitos e uma maior integração vertical em mercados lícitos para apoiar suas atividades criminosas.

Nesse contexto, uma das principais conclusões deste trabalho é que um Poder Judiciário mais eficaz na garantia do direito humano de acesso à justiça para os segmentos mais vulneráveis da população, combinado com uma maior eficácia no confisco judicial de ativos criminosos ligados

${ }^{45}$ Cf. WILLIAMSON, Oliver. The Economics of Organization: The Transaction Cost Approach. The American Journal of Sociology, Vol. 87, 3, 1981; e WILLIAMSON, Oliver. Transaction Costs Economics: An Introduction. Economics Discussion Papers, No. 2007-3, 2007. Disponível em: <http://www.economicsejournal.org/economics/discussionpapers/2007-3/at download/file>. Acesso em: 12 de fevereiro de 2018.

${ }^{46}$ Cf. BUSCAGLIA, Edgardo. An analysis of judicial corruption and its causes: an objective governing-based approach. International Review of Law and Economics, Vol. 21, 2, 2001; e BUSCAGLIA Edgardo. Investigating the links between Access to Justice and Governance Factors: An objective indicators' approach. Global Programme against Corruption Research and Scientific Series (United Nations Center for International Crime Prevention), No. CICP-13, 2001. 
à corrupção no domínios político, eleitoral e de contratações públicas, representará não apenas uma maneira de melhorar a dissuasão/punição das organizações criminosas, mas também de propiciar uma ambiente livre de bolhas de proteção sociopolítica, em que estas mesmas organizações criminosas prosperam.

Parece natural associar o poder estatal às capacidades institucionais de resolução de conflitos, mas, desde o início da história escrita, pode-se constatar a existência de vários mecanismos formais e informais de resolução de litígios que coexistem dentro de um domínio social. Exemplos são encontrados nos mecanismos de resolução de litígios oferecidos pela feiras comerciais na Europa medieval ${ }^{47}$ ou, contemporaneamente, nas experiências de resolução interna de conflitos em Afeganistão, Colômbia, Congo, México, Nigéria, África do Sul e Sudão do Sul. ${ }^{48}$ Para conflitos interpessoais ou intergrupais mais simples, esses mecanismos coletivos não estatais frequentemente fornecem soluções relativamente efetivas (em relação aos tribunais oficiais corruptos politicamente e judicialmente) em termos de legitimidade social e percepção dos usuários sobre transparência processual, eficiência aprimorada, resoluções vinculativas, maior qualidade de decisões e menor complexidade administrativa do que o judiciário do Estado. ${ }^{49}$

A inovação do setor privado em MARD nacionais e transnacionais, geralmente, ocorre entre multinacionais ou grandes empresas nacionais $\mathrm{e}$

${ }^{47}$ Cf. BERNSTEIN, Lisa. Merchant Law in a Merchant Court: Rethinking the Code's Search for Immanent Business Norms. University of Pennsylvania Law Review, Vol. 144, 5, 1996; BUSCAGLIA, Edgardo; DAKOLIAS, Maria. Comparative International Study of Court Performance Indicators: A Descriptive and Analytical Account. The World Bank (Legal and Judicial Reform Unit), Report No. 20.177, 1999; e GREIF, Avner; MILGROM, Paul; WEINGAST, Barry. Coordination, Commitment and Enforcement: The Case of the Merchant Guild. Journal of Political Economy, Vol. 102, 4, 1994.

${ }^{48}$ Cf. BUSCAGLIA, Edgardo. An analysis of judicial corruption and its causes: an objective governing-based approach. International Review of Law and Economics, Vol. 21, 2, 2001; e BUSCAGLIA Edgardo. Investigating the links between Access to Justice and Governance Factors: An objective indicators' approach. Global Programme against Corruption Research and Scientific Series (United Nations Center for International Crime Prevention), No. CICP-13, 2001.

${ }^{49} \mathrm{Cf}$. BUSCAGLIA Edgardo. Investigating the links between Access to Justice and Governance Factors: An objective indicators' approach. Global Programme against Corruption Research and Scientific Series (United Nations Center for International Crime Prevention), No. CICP-13, 2001. 
indivíduos relativamente abastados. ${ }^{50}$ No entanto, entre indivíduos marginalizados social, econômica ou etnicamente em comunidades com baixo poder aquisitivo e no meio de lacunas e falhas estatais, as frequentes arbitragem, comitês de prevenção de disputas e serviços de mediação privada são prestados monopolisticamente por organizações não estatais armadas. Este é o caso, por exemplo, dos grupos de tráfico de drogas em Faryab no norte do Afeganistão; das forças paramilitares das FARC e AUC em Pasto e Putumayo, departamentos da Colômbia durante a década de 90 até 2005; e a combinação de arbitragem e mediação fornecidos por redes criminosas dentro dos Mai-Mai, grupos armados no Leste da República Democrática do Congo, região de Kivu do Norte e do Sul. ${ }^{51}$

Pesquisa empírica anterior analisou as vantagens comparativas de mecanismos informais de resolução de disputas de terras em 16 países. ${ }^{52}$ As disputas de terra entre as famílias rurais de baixa renda foram caracterizadas por litígios de posse sobre pequenas parcelas de terra. A maioria dessas famílias não tinha acesso aos serviços públicos em geral e, em especial, à prestação jurisdicional. ${ }^{53}$ No entanto, em pesquisas domiciliares, a maioria das famílias afirmou que quando confrontadas com conflitos relacionados com propriedade, dívidas ou herança, buscavam a resolução informal de litígios via órgãos comunitários ou mesmo por meio de autoridades públicas do Poder Executivo, fora do sistema judicial, como prefeitos ou governadores. Esta pesquisa empírica aplicada a famílias rurais em regiões em que os grupos armados não

${ }^{50}$ Cf. JAMIESON, Neil, MOI, Stephen, \& CHEROT, Jason. Acting outside the box: The emerging dispute resolution centres developing innovative ways to attract business. Legal Week, 07 jun. 2012. Disponível em:

$<$ http://www.legalweek.com/sites/legalweek/2012/06/07/acting-outside-the-box-theemerging-dispute-resolution-centres-developing-innovative-ways-to-attractbusiness/>. Acesso em: 12 de fevereiro de 2018.

${ }^{51}$ Cf. ARIAS, Enrique Desmond; RODRIGUES, Corinne Davis. The Myth of Personal Security: Criminal Gangs, Dispute Resolution, and Identity in Rio de Janeiro's Favelas. Latin American Politics \& Society, Vol. 48, 4, 2006.

${ }^{52}$ Cf. BUSCAGLIA Edgardo. Investigating the links between Access to Justice and Governance Factors: An objective indicators' approach. Global Programme against Corruption Research and Scientific Series (United Nations Center for International Crime Prevention), No. CICP-13, 2001.

${ }_{53}$ Cf. BUSCAGLIA Edgardo. Investigating the links between Access to Justice and Governance Factors: An objective indicators' approach. Global Programme against Corruption Research and Scientific Series (United Nations Center for International Crime Prevention), No. CICP-13, 2001. 
estatais ofereciam MARD foi baseada em dois instrumentos de pesquisa destinados a avaliar as dimensões jurídicas e econômicas do desenvolvimento social ligadas à resolução de conflitos. ${ }^{54} \mathrm{~A}$ primeira pesquisa mensurou a frequência em que as famílias buscavam serviços judiciais e MARD ao longo do tempo. Mediações, arbitragens, comitês de prevenção de disputas e combinações dos três foram os mecanismos mais comuns em nossa amostra de 16 países. Em cada um dos países, as amostras selecionadas dentro de jurisdições rurais foram estratificadas com base em fatores socioeconômicos (nível de renda, padrões de consumo e da atividade econômica, composição por idade e sexo). ${ }^{55}$ Quanto ao regime de posse da terra, as famílias rurais em 9 países tinham títulos formais ou informais para pequenas terras com menos de 5 hectares. Nos restantes 7 países, pequenos proprietários detinham menos de 9 hectares. As variáveis de governança incluáam percepções locais de transparência processual, eficiência dos mecanismos de resolução de litígios, qualidade das decisões tomadas por ambos os tribunais e por mecanismos informais de disputa, níveis de corrupção, exigibilidade de decisões e responsabilização de quem deu ensejo às decisões.

Posteriores pesquisas empíricas comparativas internacionais também endossam nossa constatação quanto ao desempenho judicial dentro de jurisdições rurais entre 2003 e $2011 .{ }^{56}$ O presente estudo empírico visa

${ }^{54}$ Cf. BUSCAGLIA Edgardo. Investigating the links between Access to Justice and Governance Factors: An objective indicators' approach. Global Programme against Corruption Research and Scientific Series (United Nations Center for International Crime Prevention), No. CICP-13, 2001; e BUSCAGLIA, Edgardo; STEPHAN, Paul. An Empirical Assessment of the Impact of Formal versus Informal Dispute Resolution on Poverty: a Governance-Based Approach. International Review of Law \& Economics, Vol. 25, 1, 2005.

${ }^{55} \mathrm{O}$ tamanho da amostra de domicílios rurais foi a seguinte: Argentina: 3749, Benim: 2891, Brasil: 6329, Bolívia: 1718, Botswana 1943, Chile, 1392, Colômbia 3178, República Democrática do Congo: 561; Guatemala: 993, Honduras: 816, Moçambique: 2193, Nicarágua 1203, Nigéria, 7921, Paraguai: 931, Peru: 1610, África do Sul: 3915; Uganda: 658; Uruguai: 719, e Venezuela: 1961. Em cada um dos países, as amostras dentro de cada uma das jurisdições selecionadas foram estratificadas de acordo com critérios socioeconômicos (nível de renda, padrões de comércio e atividade econômica, distribuição etária, composição de gênero, etc.).

${ }^{56}$ Cf. BUSCAGLIA, Edgardo. Dispute resolution mechanisms provided by violent nonstate actors: An international comparative analysis of causes and consequences. In: Stefano Ruzza; Anja Jakobi; Charles Geisler (eds.). Non-State Challenges in a ReOrdered World: The Jackals of Westphalia. London: Routledge, 2015. 
corroborar as conclusões de Buscaglia, mas, neste caso, aplicado ao crime organizado e sua relação com a corrupção política que atinge os sistemas judiciais dos 20 países amostrados, e o acesso à justiça em tais tipos de casos..$^{57}$ Dentro deste recorte, Buscaglia e este estudo jurimétrico de 2017 reconfirmam que Botsuana, Chile, Colômbia e Uruguai experimentaram melhorias no desempenho judicial relativas a processos judiciais envolvendo o crime organizado, corrupção política e confisco de ativos. ${ }^{58}$ Além disso, após um período de 2 anos, estes mesmos 4 países experimentaram uma maior demanda por serviços judiciais, diminuindo a busca por mecanismos informais de resolução de litígios oferecidos pelas redes criminosas armadas não estatais.

Em suma, nossos dois levantamentos documentando experiências de resolução de conflitos agrários de famílias rurais (de acordo com usuários de tribunais e usuários de MARD), explicados e analisados anteriormente na literatura ${ }^{59}$, mostraram consistentemente que:

(1) As famílias rurais, dentro dos $20 \%$ da escala de valor líquido em cada país, buscam a resolução de conflitos agrários por meio de mecanismos informais de resolução de litígios, sendo estes percebidos como mais legítimos, menos corruptos, menos complexos e mais eficientes do que os mecanismos judiciais;

(2) Os acordos de resolução de conflitos usando mecanismos judiciais formais diminuíram a escala de valor líquido envolvendo as famílias rurais, enquanto as famílias rurais que procuram MARD experimentam aumento no mesmo índice após a decisão informal; e

${ }^{57}$ Cf. BUSCAGLIA, Edgardo. Dispute resolution mechanisms provided by violent nonstate actors: An international comparative analysis of causes and consequences. In: Stefano Ruzza; Anja Jakobi; Charles Geisler (eds.). Non-State Challenges in a ReOrdered World: The Jackals of Westphalia. London: Routledge, 2015.

${ }^{58}$ Cf. BUSCAGLIA, Edgardo. Dispute resolution mechanisms provided by violent nonstate actors: An international comparative analysis of causes and consequences. In: Stefano Ruzza; Anja Jakobi; Charles Geisler (eds.). Non-State Challenges in a ReOrdered World: The Jackals of Westphalia. London: Routledge, 2015.

${ }^{59}$ Cf. BUSCAGLIA, Edgardo. An analysis of judicial corruption and its causes: an objective governing-based approach. International Review of Law and Economics, Vol. 21, 2, 2001; e BUSCAGLIA, Edgardo; STEPHAN, Paul. An Empirical Assessment of the Impact of Formal versus Informal Dispute Resolution on Poverty: a GovernanceBased Approach. International Review of Law \& Economics, Vol. 25, 1, 2005. 
(3) Os países com uma maior disponibilidade de opções de resolução formal e informal de litígios agrários também são países em que o acesso a esses mecanismos é oferecido a um custo menor em proporção ao valor do imóvel em questão (ou seja, o custo direto de acesso em proporção ao valor do terreno em disputa). Esse é um indicador do acesso à justiça como um direito humano, ou, em outras palavras, uma análise econômica do direito humano de acesso aos mecanismos de resolução de litígios. O gráfico abaixo aborda esta descoberta empírica ao fornecer tais provas abrangendo 16 países. Cada ponto no gráfico indica a posição do país em termos de número de MARD disponíveis e o respectivo custo de acesso. O gráfico abaixo mostra uma relação inversa entre o número e a diversidade de mecanismos de resolução de litígios, em cada país, medida no eixo vertical através de um índice do número de mecanismos judiciais formais e MARD disponíveis dentro de regiões onde também operam os grupos de crime organizado. $\mathrm{O}$ custo total de acesso à resolução de litígios como parte das propriedades em jogo nas disputas é medido no eixo horizontal. O gráfico abaixo mostra uma relação inversa entre as duas variáveis, de modo que um país que apresenta maior diversificação em seus mecanismos de resolução de litígios apresentará custos menores para acessá-los. Essa análise econômica do direito humano de acesso aos mecanismos de resolução de litígios atesta a importância da redução de custos de acesso, fornecendo um conjunto diversificado de alternativas de resolução de litígios para os segmentos mais marginalizados da população. 


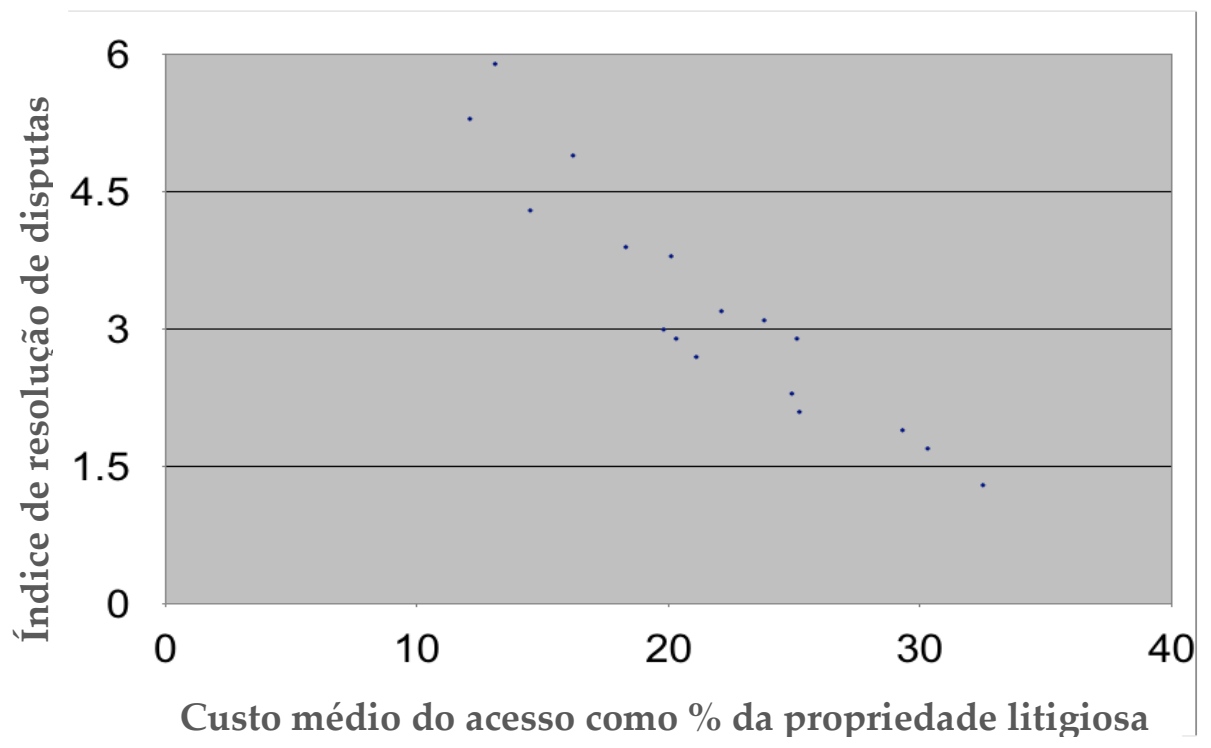

Conforme mencionado acima, os canais informais para a resolução de conflitos podem ser mecanismos de ordem comunitária ou tribal, podendo ainda serem fornecidos por redes criminosas e insurgências armadas. Por exemplo, em Botsuana e na Colômbia, os conflitos envolvendo títulos de terra de pequenas propriedades rurais encontramse principalmente enraizadas em questões de dívidas e heranças. ${ }^{60} \mathrm{Os}$ órgãos informais tribais, rurais ou de bairro geralmente são compostos de 2 a 7 membros (dependendo do país amostrado) e em muitos (mas não todos) os casos gozam de legitimidade, a qual emerge de uma liderança religiosa ou comunitária ou de prestígio social como provedores de serviços políticos, sociais, de saúde ou mesmo de bens sociais militares e políticos, como processos eleitorais, escolas religiosas, centros básicos de saúde e proteção social paramilitar. Por exemplo, os Painéis ou Conselhos de Reclamação, na Colômbia, são compostas de três "destacados moradores locais" selecionados por um Conselho Rural (Parroquias Vecinales) que gozam de legitimidade popular. ${ }^{61}$ Embora a decisão do

60 WOJKOWSKA, Ewa. Doing justice: How Informal Justice Systems can contribute. New York, NY: United Nations Development Programme, 2006.

${ }^{61}$ Cf. BUSCAGLIA Edgardo. Investigating the links between Access to Justice and Governance Factors: An objective indicators' approach. Global Programme against Corruption Research and Scientific Series (United Nations Center for International Crime Prevention), No. CICP-13, 2001. 
Conselho não seja juridicamente vinculante, essa recebe apoio tácito de autoridades municipais. Departamentos dentro dos governos municipais de três regiões colombianas costumavam fazer referência às decisões do "Conselho" para fundamentar suas decisões. ${ }^{62}$ As decisões do Conselho não admitem recurso e os mecanismos informais de controle social, geralmente, levam a seu cumprimento. Nos países que relatam a resolução de disputas por atores não estatais com base em MARD tradicionais, estudos anteriores descobriram que a diminuição do desempenho judicial em casos de disputas por terras (número de processos, atrasos maiores e frequências mais altas de abusos substantivos de discrição judicial) são acompanhados lado a lado de demanda mais frequente de MARD pelas populações rurais. Por exemplo, Congo e Moçambique, cujos tribunais civis têm os piores desempenhos em casos ligados a disputas agrárias, foram associados a um aumento nas famílias rurais que procuram mecanismos de resolução de litígios informais fornecidos por organizações armadas não estatais (por exemplo, Mai-Mai) ou por MARD tradicionais ofertados pelos anciãos. ${ }^{63}$ Padrões similares de deterioração no desempenho judicial (de acordo com a Tabela 1 acima) e maior demanda por MARD informais foram encontrados na Argentina, Benin, Bolívia, Honduras, Guatemala, México, Moçambique, Nigéria, Paraguai, Peru, Suriname e Venezuela.

\section{A OFERTA DE MARD COMO SUPORTE PARA A INTEGRAÇÃO VERTICAL DAS REDES CRIMINOSAS E A CORRUPÇÃO POLÍTICA}

Há uma premissa fundamental (e não apenas uma suposição) na análise econômica do crime organizado. ${ }^{64}$ Buscaglia \& Gonzalez Ruiz e Buscaglia apresentam estudos de casos que evidenciam que todas as

${ }^{62}$ Cf. BUSCAGLIA, Edgardo; STEPHAN, Paul. An Empirical Assessment of the Impact of Formal versus Informal Dispute Resolution on Poverty: a Governance-Based Approach. International Review of Law \& Economics, Vol. 25, 1, 2005.

${ }^{63}$ Cf. BUSCAGLIA, Edgardo; STEPHAN, Paul. An Empirical Assessment of the Impact of Formal versus Informal Dispute Resolution on Poverty: a Governance-Based Approach. International Review of Law \& Economics, Vol. 25, 1, 2005.

${ }^{64}$ Crime organizado, tal como definido no Artigo $2^{\circ}$ da Convenção das Nações Unidas contra o Crime Organizado e seus protocolos. Disponível em:

$<$ http://www.unodc.org/documents/treaties/UNTOC/Publications/TOC\%20Conventio

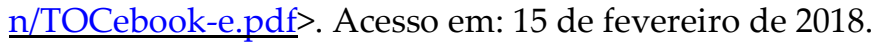


redes criminosas transnacionais dedicadas à prática de diversos tipos de crimes complexos em uma base estável e sustentável sempre visam monopolizar mercados por meio de integrações horizontais e verticais dentro de seus mercados legais e ilegais. ${ }^{65}$

As integrações verticais e horizontais em mercados legais e ilegais são o objetivo natural de qualquer rede de crime organizado destinada a estabilizar e prever suas cadeias de abastecimento de insumos-chave dos mercados lícitos em meio à concorrência com outras redes criminosas violentas. Nesse contexto, as integrações verticais e horizontais são sempre destinadas a reduzir a incerteza e o comportamento oportunista dentro da cadeia ${ }^{66}$, a fim de produzir bens (por exemplo, fentanil) ou serviços (por exemplo, trabalho forçado via tráfico de pessoas). Além disso, a diversificação dos mercados ilegais, juntamente com as integrações horizontais e verticais nos mercados legais e ilegais, ampliam o alcance dos bens e serviços ilícitos/lícitos produzidos, reduzindo o risco de colocar "todos os ovos em uma única cesta", apenas no caso de aumentos no confisco judicial ou da concorrência ameaçarem as suas operações comerciais ou apenas no caso de os desenvolvimentos do mercado tornarem um ou mais dos seus bens e serviços não rentáveis. Além disso, o aprimoramento da integração vertical e horizontal permite que organizações criminosas reduzam seus custos de transação prospectivos de condução de lavagem de dinheiro através de seus próprios negócios legais.

No entanto, integrações horizontais e verticais de organizações criminosas também abrangem o controle parcial dos mercados de trabalho para alimentar os serviços necessários no âmbito das referidas cadeias de fornecimento que, por sua vez, exigem uma certa quantidade de controle social por essas mesmas organizações criminosas transnacionais, a fim de obter mão-de-obra voluntária. O controle social

${ }^{65}$ Cf. BUSCAGLIA, Edgardo; GONZÁLEZ RUIZ, Samuel. The Factor of Trust and the Importance of Inter-Agency Cooperation in the Fight against Transnational Organised Crime: The US-Mexican Example. The Management of Border Security in NAFTA: Imagery, Nationalism, and the War on Drugs, Vol. 15, 1, 2005; e BUSCAGLIA, Edgardo. Dispute resolution mechanisms provided by violent non-state actors: An international comparative analysis of causes and consequences. In: Stefano Ruzza; Anja Jakobi; Charles Geisler (eds.). Non-State Challenges in a Re-Ordered World: The Jackals of Westphalia. London: Routledge, 2015.

${ }^{66}$ Cf. WILLIAMSON, Oliver. The Economics of Organization: The Transaction Cost Approach. The American Journal of Sociology, Vol. 87, 3, 1981; e GROSSMAN, Sanford; HART Oliver. The Costs and Benefits of Ownership: A Theory of Vertical and Lateral Integration. Journal of Political Economy, Vol. 94, 4, 1986. 
exercido por grupos de criminalidade organizada transnacional ocorre de diversas formas. Por exemplo, na região mexicana de Michoacán, existiam duas organizações criminosas conhecidas como Familia e Caballeros Templarios, desfrutando de um monopólio regional virtual no fornecimento de drogas sintéticas, juntamente com a integração horizontal em outros 12 mercados ilícitos e em pelo menos 5 setores econômicos lícitos (por exemplo, produção de abacate, empresas de transporte, empresas de construção, serviços de saúde preventiva, fornecimento de alimentos para varejo e hotéis no setor de turismo). Nesse contexto, Buscaglia descreve visitas de campo in situ a regiões em Michoacán, onde esses mesmos dois grupos criminosos forneciam bens sociais dentro de suas regiões controladas (por exemplo, Mil Cumbres), tais como infraestrutura de irrigação de água para as suas unidades de produção rural de abacates, dedicado à infraestrutura de esgoto, a construção de escolas e até igrejas, juntamente com o fornecimento de mecanismos de resolução de litígios para a população geral regional sob o seu controle social. ${ }^{67}$ Em contrapartida, ambas as organizações criminosas obtinham um valioso fornecimento de mão-de-obra e terra para satisfazer a suas necessidades nos mercados legais e ilegais.

Esses tipos de integrações verticais e horizontais como explicado acima, sempre ocorrem em meio a diversos vácuos estatais no fornecimento de bens e serviços públicos (por exemplo, água, educação, saúde e justiça), conforme evidenciado em Buscaglia. ${ }^{68} \mathrm{Em}$ outras palavras, a falta de acesso público aos serviços judiciais por segmentos de populações rurais economicamente vulneráveis, juntamente com as incapacidades políticas vinculadas à corrupção na aplicação da lei para implementar medidas de confisco de ativos, permitiu que as redes criminosas expandissem verticalmente suas infraestruturas comerciais ao mesmo tempo em que forneciam mecanismos alternativos de resolução de litígios à população como uma forma de controle social para obter mão-de-obra e dispor de propriedades privadas das populações "cativas".

Vinte países estão identificados na coluna 1 da Tabela 2 abaixo. Esses países foram amostrados com base na existência de regiões em que as redes de crime organizado ofertam bens sociais (tais como os MARD oferecidos pela Familia Michoacana em Mil Cumbres, Michoacán, México). Dezenove desses países são os mesmos abrangidos na Tabela 1, na qual

${ }^{67}$ Cf. BUSCAGLIA, Edgardo. Vacíos de Poder en Mexico. Ciudad de México, DF:

Random House Mondadori, 2013.

${ }^{68}$ Cf. BUSCAGLIA, Edgardo. Vacíos de Poder en Mexico. Ciudad de México, DF:

Random House Mondadori, 2013.

3 JOURNAL OF INSTITUTIONAL STUDIES 2 (2017) 
são medidos os índices de eficiência judicial no trato do crime organizado relacionado à corrupção política (com exceção de Uganda, coberta apenas na Tabela 1, e do Brasil, coberto apenas na Tabela 2). Com base na análise acima, as séries temporais de dados específicos por país na Tabela 2 abaixo cobrem o período 2004-2015. Na coluna 4 abaixo, a Tabela 2 mede o número de mercados ilícitos para o fornecimento de bens e serviços cobertos em cada país por uma organização criminosa transnacional específica em dois momentos, em 2004 e em 2015 (por exemplo, uma rede criminosa de tráfico de drogas, pessoas e armas, receberia um indicador igual a 3). Na coluna 2 da Tabela 2, também medidas em dois momentos no tempo, em 2004 e em 2015, aponta-se o percentual de domicílios amostrados enfrentando disputas agrárias e utilizando MARD ofertados por um órgão tradicional ou por uma organização criminosa. ${ }^{69} \mathrm{~A}$ coluna 3 denomina cada organização criminosa transnacional ofertando MARD e a coluna 5 mede a escala ( 1 a 6 ) da cadeia de fornecimento de bens lícitos e ilícitos e serviços controlados por cada organização criminosa em setores econômicos.

A hipótese a ser testada afirma o seguinte: a eficiência dos sistemas judiciais na realização de confisco de ativos de redes criminosas envolvidas em corrupção política dentro dos domínio de financiamento eleitoral e licitações públicas, medidas na Tabela 1, com um distanciamento de dois anos, causam um impacto significativo: (1) sobre as diferenças nas integrações verticais dos empreendimentos criminosos transnacionais em âmbitos lícitos (medidas na coluna 3 da Tabela 2 abaixo); (2) sobre as diferenças na diversidade dos mercados criminosos abrangidos por empreendimentos criminosos transnacionais; (3) sobre as diferenças de frequência de oferta/demanda de mecanismos alternativos de resolução de litígios em regiões onde essas mesmas organizações criminosas transnacionais atuam no fornecimento de bens sociais.

A coluna 2 da Tabela 2 mede a porcentagem de nossas amostras regionais baseadas em países em que famílias rurais que procuram MARD de duas fontes: órgãos tradicionais de anciãos e organizações criminosas transnacionais armadas. Os processos judiciais que examinamos também foram relacionados a acusações de corrupção política. Cada um desses grupos de crime organizado é identificado na coluna 3. As percentagens das amostras de famílias demandado MARD

${ }^{69}$ Com uma amostra maior e ampliada série temporal, pode-se também testar a causalidade não paramétrica de Granger. Cf. GRANGER, Clive. Investigating Causal Relations by Econometric Models and Cross-Spectral Methods. Econometrica, Vol. 37, 3, 1969, p. 424-438. 
são medidas em dois pontos no tempo, em 2004 e 2015, dentro de cada região onde as organizações criminosas atuam no fornecimento de bens sociais (tais como água, saúde preventiva, infraestrutura, ou resolução de litígios). Por exemplo, na fronteira da Albânia com o Kosovo em 2004, descobrimos que $4 \%$ da nossa amostragem procurava MARD de organismos informais tradicionais, enquanto a proporção da amostra aumentou para $8 \%$ em 2015. Nesses dois momentos e dentro desta mesma região albanesa, $2 \%$ da nossa amostra de famílias rurais demandaram MARD da organização criminosa Kula, em 2004, enquanto a proporção de nossa amostra de famílias rurais de 2015 aumentou para 5\%. Vale ressaltar que, durante esse mesmo período, a Tabela 1 demostra uma deterioração acentuada do desempenho judicial albanês nesta mesma região, com uma queda de $24 \%$ nas taxas de solução (ou seja, aumento acentuado dos atrasos de tempo), juntamente com um aumento de $55 \%$ nos erros judiciais ao realizar confisco de ativos contra a organização criminosa de Abazi e Boriçi. Além disso, a coluna 4 da Tabela 2 mostra que a rede Abazi e Boriçi esteve envolvida em 12 tipos de crimes organizados em 2004 e 21 tipos de crimes organizados em 2015, incluindo o financiamento ilegal de campanhas políticas e lavagem de capitais via contratos públicos.

A quinta coluna indica o grau de integração vertical da respectiva organização criminosa em cada país. $\mathrm{O}$ indicador de integração vertical mede 6 níveis de controles de uma cadeia de suprimentos para a produção de um serviço lícito ou ilícito, com "1" indicando o controle criminoso do negócio de distribuição; "2" indicando o controle criminoso dos domínios jurídicos de distribuição e atacado; "3" indicando o controle criminoso das infraestruturas de distribuição, atacado e transporte; " 4 " indicando o controle criminoso da distribuição, atacado, transporte e produção do bem ou serviço ilegal; " 5 " indicando o controle criminoso da distribuição, atacado, transporte, produção e insumos (como uma folha de coca); e, " 6 " indicando o controle criminoso da distribuição, atacado, transporte, produção, insumos e infraestruturas de varejo. Ao aplicar essa mesma escala de integração vertical de 1-6 às organizações criminosas albanesas Abazi e Boriçi / Kula, vemos, na coluna 5 do quadro 2 abaixo, que sua integração vertical no âmbito jurídico-econômico da Albânia e do Kosovo expandiu-se do controle legal da distribuição e da cadeia de suprimentos por atacado em 2004 para o controle legal das distribuição, atacado, transporte, produção, insumos e infraestrutura de varejo em 2015. Em outras palavras, o aumento do indicador de integração vertical da rede criminosa de Kula reflete o fracasso das autoridades judiciais em confiscar ativos criminosos ligados à corrupção política e, portanto, a incapacidade de controlar a expansão 
econômica da rede de crime organizado albanês nos domínios jurídicos. Dessa forma, a Tabela 2 demonstra os impactos hipotéticos de melhorias ou deteriorações no desempenho judicial no confisco de ativos vinculados a crimes econômicos e corrupção política - nas diminuições ou aumentos na diversificação de atividades criminosas organizadas, na oferta de MARD e nas reduções ou expansões na integração vertical de organizações criminosas específicas na esfera da licitude, facilitando assim a lavagem de dinheiro.

A Tabela 2 abaixo também mostra que o Chile, a Colômbia e o Uruguai experimentam menos demanda por MARD fornecidas por organizações criminosas transnacionais em 2015, em relação a 2004, menor diversidade de bens e serviços ilegais e menor integração vertical em 2015, em relação a 2004. Em outras palavras, Chile, Colômbia e Uruguai estão controlando a expansão transnacional das suas organizações criminosas regionais amostradas dentro da empresa verticalmente integrada e dos domínios políticos e também controlando a expansão na diversidade de crimes e redução da oferta de MARD por essas mesmas redes criminosas.

Tabela 2 - MARD e integração vertical de organizações criminosas transnacionais

\begin{tabular}{|c|c|c|c|c|c|}
\hline País & $\begin{array}{r}\text { Percent } \\
\text { famílias rur } \\
\text { subr } \\
\text { (grupos ar } \\
\end{array}$ & $\begin{array}{r}\text { al da amostra de } \\
\text { ais com disputas } \\
\text { netidas a MARD } \\
\text { nados vs. grupos } \\
\text { não armados) } \\
\text { MARD } \\
\text { providos por } \\
\text { organizações } \\
\text { criminosas } \\
\text { armadas } \\
\text { paraestatais } \\
(2004 / 2015)\end{array}$ & $\begin{array}{r}\text { Denominação de organizações criminosas } \\
\text { transnacionais dedicadas a até } 23 \text { tipos de crimes } \\
\text { econômicos complexos }\end{array}$ & $\begin{array}{r}\text { Escopo } \\
\text { (número) de } \\
\text { atividades } \\
\text { criminosas } \\
\text { da } \\
\text { organização } \\
\text { criminosa } \\
(2004 / 2015)\end{array}$ & $\begin{array}{r}\text { Integração } \\
\text { vertical de } \\
\text { operações } \\
\text { comerciais } \\
\text { lícitas } \\
\text { associadas a } \\
\text { atividades } \\
\text { criminosas } \\
(2004 / 2015)\end{array}$ \\
\hline Albânia & $4 / 8$ & $2 / 5$ & $\begin{array}{l}\text { Organização criminosa Kula, que controla, da Turquia, o tráfico } \\
\text { de drogas, armas e pessoas, e famílias Abazi and Boriçi } \\
\text { (Buscaglia, 2015). }\end{array}$ & 12/21 tipos & $2 / 6$ \\
\hline Argentina & $3 / 5$ & $1 / 2$ & $\begin{array}{l}\text { Famílias Sung I e Ming na Tríplice Fronteira entre Argentina, } \\
\text { Brasil e Paraguai, além do Uruguai (Hudson, 2003) }\end{array}$ & 8/18 tipos & $4 / 5$ \\
\hline Benin & $48 / 51$ & $7 / 11$ & $\begin{array}{l}\text { Grupo Kakudu operando em Benin, Togo, Nigeria e África do Sul } \\
\text { (United Nations Office on Drugs and Crime, 2005) }\end{array}$ & 11/20 tipos & $5 / 6$ \\
\hline Bolívia & $39 / 41$ & $7 / 8$ & “La Corporación” (Farer, 1999) & 6/11 tipos & $5 / 6$ \\
\hline
\end{tabular}




\begin{tabular}{|c|c|c|c|c|c|}
\hline Botswana & $53 / 37$ & $4 / 1$ & $\begin{array}{l}\text { Grupo Okavango Delta, encobrindo tráfico de pedras preciosas, } \\
\text { pessoas e drogas em Angola e Botswana (Buscaglia 2015) }\end{array}$ & $8 / 3$ tipos & $3 / 1$ \\
\hline Brasil & $38 / 21$ & $2 / 1$ & $\begin{array}{l}\text { Ambas as facções PCC e CV proveem MARD em favelas em São } \\
\text { Paulo e Rio de Janeiro (Birol \& Dal Ri Jr., 2011) } \\
\text { Famílias Sung I e Ming na Tríplice Fronteira entre Argentina, } \\
\text { Brasil e Paraguai, além do Uruguai (Hudson, 2003) }\end{array}$ & 6/10 tipos & $3 / 5$ \\
\hline Chile & $19 / 9$ & $2 / 0$ & Famílias Sung I e Ming (Buscaglia, 2015) & 3/2 tipos & $2 / 1$ \\
\hline Colômbia & $21 / 6$ & $17 / 4$ & $\begin{array}{l}\text { Diego Montoya \& Wilber Varela, Organização “Norte del Valle” } \\
\text { (Buscaglia, 2015) }\end{array}$ & $11 / 5$ tipos & $5 / 2$ \\
\hline Congo & $87 / 96$ & $87 / 96$ & $\begin{array}{l}\text { Organização Mai-Mai (Mayi-Mayi) em Kivus (Coalition to Stop } \\
\text { the Use of Child Soldiers, 2010) }\end{array}$ & 11/19 tipos & $3 / 6$ \\
\hline Guatemala & $49 / 56$ & $25 / 38$ & Organização criminosa Sinaloa (Buscaglia, 2013, 2015) & 13/21 tipos & $4 / 6$ \\
\hline Honduras & $24 / 38$ & $11 / 16$ & Organização criminosa Sinaloa (Buscaglia, 2013, 2015) & 10/19 tipos & $3 / 5$ \\
\hline Indonésia & $12 / 13$ & $4 / 3$ & Movimento Aceh Livre (GAM) (Wahyono, 2010) & 4/12 tipos & $2 / 5$ \\
\hline Moçambique & $77 / 89$ & $8 / 21$ & $\begin{array}{l}\text { Grupo Kakudu operando em Benin, Togo, Nigeria e Áfricado Sul } \\
\text { (Buscaglia, 2015) }\end{array}$ & 6/13 tipos & $3 / 6$ \\
\hline México & $12 / 29$ & $18 / 39$ & Organização criminosa Sinaloa (Buscaglia, 2013, 2015) & 18/23 tipos & $2 / 6$ \\
\hline Nigéria & $62 / 67$ & $6 / 8$ & $\begin{array}{l}\text { Grupo Kakudu operando em Benin, Togo, Nigeria e África do Sul } \\
\text { (United Nations Office on Drugs and Crime, 2005) }\end{array}$ & 11/22 tipos & $4 / 6$ \\
\hline Paraguai & $45 / 49$ & $26 / 29$ & $\begin{array}{l}\text { Famílias Sung I e Ming na Tríplice Fronteira entre Argentina, } \\
\text { Brasil e Paraguai (Hudson, 2003) }\end{array}$ & 15/19 tipos & $3 / 5$ \\
\hline Peru & $31 / 37$ & $2 / 6$ & $\begin{array}{l}\text { Organização Zevallos, associada ao Sendero Luminoso } \\
\text { (Buscaglia, 2015) }\end{array}$ & 10/18 tipos & $2 / 4$ \\
\hline África do Sul & $45 / 32$ & $1 / 3$ & $\begin{array}{l}\text { Grupo Kakudu operando em Benin, Togo, Nigeria e África do Sul } \\
\text { (Buscaglia, 2015) }\end{array}$ & 5/14 tipos & $2 / 4$ \\
\hline Uruguai & $23 / 12$ & $0 / 0$ & $\begin{array}{l}\text { Famílias Sung I e Ming na Tríplice Fronteira entre Argentina, } \\
\text { Brasil e Paraguai, além do Uruguai (Hudson, 2003) }\end{array}$ & $7 / 5$ tipos & $3 / 2$ \\
\hline Venezuela & $17 / 48$ & $2 / 9$ & $\begin{array}{l}\text { Diego Montoya \& Wilber Varela, Organização “Norte del Valle”, } \\
\text { e organização criminosa Sinaloa (Buscaglia, 2013, 2015) }\end{array}$ & $8 / 22$ tipos & $4 / 6$ \\
\hline
\end{tabular}

Testaremos a seguir a hipótese explicada acima para determinar se as melhorias judiciais no confisco de ativos ligados ao crime organizado e à corrupção política em financiamento de campanhas eleitorais e contratos públicos, medidos no Chile, Colômbia e Uruguai, entre 2004 e 2015, acompanham a diminuição da diversidade de mercados criminosos e a 
diminuição da capacidade dessas mesmas organizações criminosas para integrar-se verticalmente a fim de adquirir maior poder de mercado. $\mathrm{Na}$ coluna 2, vemos que Botsuana, Chile, Colômbia e Uruguai experimentaram diminuições nas frequências de MARD ofertados por órgãos tradicionais informais e por grupos armados (por exemplo, pelas FARC na Colômbia). Especificamente, pode-se ver que, em 2004, 21\% dos domicílios amostrados nas duas regiões da Colômbia pesquisadas procuraram assistência de grupos armados não tradicionais (juntas comunitarias) em conflitos de terras, mas apenas $6 \%$ dos domicílios amostrados recorreram a mecanismos tradicionais de resolução informal de conflitos em 2015. O papel dos grupos armados como oferecedores de MARD nessas mesmas duas amostras regionais na Colômbia também diminuiu de $17 \%$, da nossa amostra em 2004, para 4\%, em nossa amostra de domicílios em 2015. As mesmas diminuições nas frequências de MARD podem ser observadas na coluna 2 para Botsuana, Chile e Uruguai. O efeito oposto ocorre nos países em que os sistemas judiciais experimentaram as mais significativas alterações no desempenho. Congo, México e Guatemala se destacam com os piores desempenhos judiciais na amostra de 20 países em Buscaglia \& Stephan e em Buscaglia..$^{70}$ Enquanto, no Congo, a porcentagem de domicílios amostrados recebendo MARD dos grupos armados aumentou de $87 \%$, em 2004, para 96\%, em 2011, na Guatemala, o aumento foi de $25 \%$, em 2004, para $38 \%$, em 2015, e, no México, de $18 \%$ para $39 \%$ dos domicílios amostrados no mesmo período.

De acordo com a nossa hipótese de custos de transação judicial acima descrita, os piores desempenhos judiciais experimentaram crescimentos mais elevados nas frequências de demanda e oferta de MARD por grupos do crime organizado. Nossa hipótese também afirma que as organizações criminosas que ampliam a oferta de MARD estão associadas a aumentos significativos na diversificação de crimes econômicos ocorridos entre 2004 e 2015. De fato, os processos judiciais revisados por nossas equipes mostram que a rede criminosa da República Democrática do Congo aumentou a sua diversificação de 11 para 19 tipos de crimes econômicos; a rede criminosa da Guatemala aumentou de 13 tipos de crimes, em 2004, para 21, em 2015; tipos e organizações criminosas amostrados do México

${ }^{70}$ Cf. BUSCAGLIA, Edgardo; STEPHAN, Paul. An Empirical Assessment of the Impact of Formal versus Informal Dispute Resolution on Poverty: a Governance-Based Approach. International Review of Law \& Economics, Vol. 25, 1, 2005; e BUSCAGLIA, Edgardo. Dispute resolution mechanisms provided by violent non-state actors: An international comparative analysis of causes and consequences. In: Stefano Ruzza; Anja Jakobi; Charles Geisler (eds.). Non-State Challenges in a Re-Ordered World: The Jackals of Westphalia. London: Routledge, 2015. 
aumentaram os seus mercados criminosos de 18 bens e serviços, em 2004, para 23 tipos de crimes em 2015. Como poderia prever o arcabouço teórico de Williamson ${ }^{71}$, estes mesmos países experimentaram os maiores aumentos na integração vertical de organizações criminosas dentro dos âmbitos legais de sua economia. ${ }^{72}$ Especificamente em relação à rede criminosa da República Democrática do Congo, investigações judiciais identificaram operações de empresas em 5 países africanos, abrangendo 3 fases de sua cadeia de suprimento, em 2004, enquanto, em 2015, a mesma rede criminosa estava operando empresas em 7 países africanos e cobrindo todas as 6 fases da integração vertical. Os processos judiciais analisados, na Guatemala e no México, mostram que ambos os países tiveram suas redes criminosas amostradas aumentando seu alcance de integração vertical dentro de suas economias legais até o nível máximo de 6 etapas das cadeias de suprimentos, controlando a produção de insumos, a produção do bem ou serviço final, infraestrutura de transporte, redes de distribuição, domínios de atacado e varejo.

Nota-se a partir do gráfico acima que a inércia de instituições judiciais e os aumentos nas demandas por MARD para resolver litígios tendem a reduzir os custos médios de acesso como proporção do valor em questão na disputa, somente se houver um aumento no número e no escopo dos MARD disponíveis. No entanto, como já explicado, pesquisas realizadas junto a famílias em Buscaglia e em Buscaglia \& Stephan mostram que nem todos os mecanismos informais de resolução de litígios são semelhantes. ${ }^{73}$ Mecanismos informais de resolução de litígios fornecidos

${ }^{71}$ WILLIAMSON, Oliver. The Economics of Organization: The Transaction Cost Approach. The American Journal of Sociology, Vol. 87, 3, 1981.

72 Esses crimes econômicos incluem: tráfico ilícito de drogas; "fraude nigeriana" ou

"conto do vigário" (advanced fee scam); fraudes e outros tipos de crimes cibernéticos; tráfico de pessoas; contrabando de diamantes; falsificação de documentos e passaportes; contrabando de cigarros; tráfico de peças e veículos roubados; branqueamento de capitais; fabrico e tráfico de armas; roubo com emprego de arma de fogo; furto de combustível; pirataria; contrafação; tráfico de recursos naturais; tráfico de antiguidades e propriedade cultural. Cf. BUSCAGLIA, Edgardo; VAN DIJK, Jan. Controlling Organized Crime and Corruption in the Public Sector. Forum on Crime and Society, Vol. 3, 1-2, 2003.

${ }^{73}$ Cf. BUSCAGLIA, Edgardo. An analysis of judicial corruption and its causes: an objective governing-based approach. International Review of Law and Economics, Vol. 21, 2, 2001; BUSCAGLIA Edgardo. Investigating the links between Access to Justice and Governance Factors: An objective indicators' approach. Global Programme against Corruption Research and Scientific Series (United Nations Center for 
por grupos criminosos armados no Afeganistão (tais como as organizações Noorzai e Juma Khan) ou no Congo (Mai-Mai nas regiões orientais do Kivu do Norte e do Sul) que não oferecem a possibilidade de validação de suas decisões por autoridades formais, em nível local ou judicial, apresentam desvantagens comparativas sobre os fornecidos pelos mecanismos tradicionais, como Jirgas e Shuras, no Afeganistão e no Paquistão, ou Juntas Parroquiales na Colômbia.

Grande parcela dos fundamentos teóricos sobre organizações criminosas encontradas nas obra seminal de Schelling e suas extensões refletidas em Gambetta aborda a análise das bases sociais de organizações criminosas como estruturas alternativas de governança pública emergentes frente a Estados fracos ou ausentes, submetidos a diferentes tipos de falhas institucionais. ${ }^{74}$ Nesse contexto, uma das premissas na análise dos 20 países ora abordada é que os mecanismos alternativos de resolução de litígios são um canal para que as associações criminosas capturem o tecido social a fim de obter insumos econômicos para a produção de bens e serviços ilegais (por exemplo, terra e trabalho) em troca de estruturas mafiosas de proteção social. Buscaglia mostra que, quanto mais uma associação criminosa diversifica suas atividades econômicas com o tráfico de drogas, pessoas, armas, jogos de azar, crimes cibernéticos, contrafação e contrabandos diversos, mais ela precisa exigir mão-de-obra e capital de seu entorno em troca da oferta de serviços sociais (por exemplo, MARD) com uma penetração mais profunda no tecido social, a fim de minimizar os custos de transação da organização criminosa como previsto por Williamson. ${ }^{75}$ Neste contexto, a Tabela 2 acima mostra que todos os grupos criminosos transnacionais listados são

International Crime Prevention), No. CICP-13, 2001; e BUSCAGLIA, Edgardo; STEPHAN, Paul. An Empirical Assessment of the Impact of Formal versus Informal Dispute Resolution on Poverty: a Governance-Based Approach. International Review of Law \& Economics, Vol. 25, 1, 2005.

${ }^{74} \mathrm{Cf}$. SCHELLING, Thomas. What is the Business of Organized Crime? The American Scholar, Vol. 40, 4, 1971; e GAMBETTA, Diego. The Sicilian Mafia: The Business of Private Protection. Cambridge, MA: Harvard University Press, 1993.

${ }^{75}$ Cf. BUSCAGLIA, Edgardo. Dispute resolution mechanisms provided by violent nonstate actors: An international comparative analysis of causes and consequences. In: Stefano Ruzza; Anja Jakobi; Charles Geisler (eds.). Non-State Challenges in a ReOrdered World: The Jackals of Westphalia. London: Routledge, 2015; e WILLIAMSON, Oliver. Transaction Costs Economics: An Introduction. Economics Discussion Papers, No. 2007-3, 2007. Disponível em: $<\underline{\text { http://www.economics- }}$ ejournal.org/economics/discussionpapers/2007-3/at download/file>. Acesso em: 12 de fevereiro de 2018. 
diversificados em seu âmbito de atividades econômicas e a maior diversificação de mercados ilícitos está associada a uma maior imersão no tecido social das comunidades, através da oferta mais frequente de MARD. Em áreas onde as organizações criminosas possuem maior diversificação de seus negócios em mercados legais e ilegais, essas também irão buscar maior apoio logístico e de recursos humanos para sustentar suas operações. Essa maior captura do tecido social implica a oferta mais frequente de bens e serviços sociais, como a resolução de conflitos, confirmando assim o efeito previsto pela análise econômica das teorias de acesso à justiça em Buscaglia e, posteriormente, em Milhaupt $\&$ West. $^{76}$

Com base nos dados jurimétricos, nas Tabelas 1 e 2, testaremos esta hipótese executando uma Regressão Multiplicativa Não-Paramétrica (NPMR). ${ }^{77}$ A hipótese a ser testada afirma que a diminuição nos indicadores de eficiência judicial que abrangem uma amostra estratificada de casos judicias, em 20 países, abordando confisco de ativos pertencentes a organizações criminosas relacionados a dois tipos de corrupção política (financiamento ilegal de campanha e contratos públicos), com um distanciamento de cinco anos, não está significativamente correlacionada ao (1) aumento da integração vertical lícita de organizações criminosas; (2) aumento na diversidade de atividades criminosas; e (3) aumento nas frequências de oferta de mecanismos alternativos de resolução de litígios por essas mesmas organizações criminosas.

${ }^{76}$ Cf. BUSCAGLIA, Edgardo. Legal and Economic Development: The Missing Links. Journal of Interamerican Studies and World Affairs, Vol. 35, 4, 1994; BUSCAGLIA Edgardo. Investigating the links between Access to Justice and Governance Factors: An objective indicators' approach. Global Programme against Corruption Research and Scientific Series (United Nations Center for International Crime Prevention), No. CICP-13, 2001; e MILHAUPT, Curtis; WEST, Mark. The Dark Side of Private Ordering: An Institutional and Empirical Analysis of Organized Crime. University of Chicago Law Review, Vol. 67, 1, 2000.

${ }^{77}$ A regressão multiplicativa não-paramétrica (NPMR) é uma regressão, como outros métodos de regressão, que estima variáveis dependentes com base em um ou mais preditores. A NPMR pode ser usada como um método de regressão, desde que assumido o seguinte: 1) a distribuição da variável dependente é desconhecida; 2) os preditores interagem entre si, em causalidade conjunta, sobre a variável dependente ou, em outras palavras, a resposta a um preditor provavelmente dependerá de outros preditores; e 3) a resposta é uma variável quantitativa ou binária (0/1). 
Tabela 3 - Teste estatístico

Rejeite a Hipótese se o resultado do teste estatístico for $\geq$ ao valor crítico $(\alpha=5 \%)$

\begin{tabular}{lccc} 
& Integração vertical & Diversidade de mercados & MARD \\
\hline (Soma dos rankings) $^{2}$ & 319251 & 71481 & 49270 \\
Número de colunas & 2. & 2. & 2 \\
Número de linhas & 20. & 20. & 20 \\
Teste estatístico & 10.057. & 12.613 & 9.501
\end{tabular}

Todos os testes são estatisticamente significantes em um grau de 5\%

Na Tabela 3, rejeitamos a hipótese acima com a conclusão de que as diminuições na eficiência dos sistemas judiciais no tratamento desses casos de confisco criminal, com um distanciamento de cinco anos, fazem uma diferença significativa no aumento do poder de mercado e na integração vertical de organizações criminosas nos setores econômicos legais e, assim, aumenta as capacidades das redes criminosas de produzir uma gama mais diversificada de bens e serviços ilegais e legais. Portanto, a Tabela 3 confirma que o aumento dos indicadores de eficiência judiciais no caso de sanções penais na Tabela 1 acompanha uma diminuição na diversidade de atividades criminosas e com frequências mais baixas na procura por mecanismos alternativos de resolução de litígios por redes de crime organizado, medida na Tabela 2.

\section{CONCLUSÃo}

A melhoria na eficiência judicial no confisco de ativos provenientes de crimes em face de organizações armadas dedicadas ao tráfico de pessoas, drogas, armas, ao financiamento ilícito de campanhas eleitorais, lavagem de dinheiro por meio de contratos públicos, e muitos outros tipos de crimes econômicos complexos e sérios, constitui um dos principais objetivos das convenções internacionais das Nações Unidas ratificadas por mais de 170 países em todo o mundo e pelos 20 países amostrados neste estudo.

Além disso, uma maior eficiência judicial no confisco de ativos criminosos em face desses tipos de redes organizadas transnacionais envolvidas em corrupção política em muitos países, ao mesmo tempo, fortalece o direito humano de participar de eleições políticas hígidas, sem 
coerção, além de também fortalecer o acesso à justiça pelas vítimas do crime organizado, para que possam receber uma indenização por danos civis e penais. Países como a Itália avançaram na consecução de diplomas legais disciplinadores dos direitos explícitos das vítimas do crime organizado de serem diretamente atendidas e indenizadas via processos de confisco de ativos do crime organizado. Portanto, os indicadores da eficiência judicial no confisco de bens nas mãos do crime organizado também podem ser lidos como indicadores de exercício dos direitos humanos de votar e de acessar à justiça. Nesse sentido, este estudo tem como objetivo fornecer uma abordagem empírica para a medição e avaliação desses dois direitos políticos e civis e de outros direitos humanos.

Como um tipo específico de grupo armado não estatal, as organizações criminosas dependem de seus mecanismos mafiosos de proteção, fornecendo bens sociais (como a resolução de conflitos) aos segmentos mais marginalizados da população como forma de garantir as cadeias de abastecimento de terra e mão-de-obra barata para diversificar seus negócios econômicos legais e ilegais. Estes esquemas mafiosos de proteção do crime organizado sempre cobrem vácuos deixados por falhas conspícuas do Estado no fornecimento de bens públicos (por exemplo, água, segurança básica ou serviços judiciais). A análise jurimétrica abordada acima demonstra esse ponto. Além disso, faz parte desse processo a prática perversa de capturar o tecido social das comunidades em que os crimes econômicos são perpetrados. Nessa dinâmica quid pro $q u o$, segmentos da sociedade estão sujeitos a esquemas mafiosos de proteção por grupos não estatais por meio de diversos tipos de mecanismos de resolução de disputas no estilo tradicional das facções organizadas russas, explorado por Farer. ${ }^{78}$

À medida que as organizações criminosas compostas por atores não estatais geram diferentes tipos de negócios lucrativos (por meio de violência física, coletiva ou econômica) em associação com redes criminosas de políticos, essas mesmas organizações criminosas se alimentam da existência de falhas estatais regulatórias e vácuos institucionais (i.e. Estados que estão demasiadamente ausentes ou que impõe dificuldades à vida das pessoas, causando assim altos custos de transação nas interações sociais). Esses tipos de falhas estatais incluem as incapacidades do sistema judicial, sua extrema complexidade processual, a corrupção desenfreada e a sua falta de acesso aos canais de resolução de litígios. Nesse tipo de ambiente, caracterizado pela incerteza jurídica e

${ }^{78}$ FARER, Tom. (ed). Transnational Crime in the Americas: An Inter-American

Dialogue Book. New York, NY: Routledge, 1999. 
judicial, torna-se difícil o planejamento de produção e de investimento. Essa incerteza ligada aos direitos de propriedade afeta todos os segmentos da população (ricos, classe média e pobres), mas afeta mais os mais pobres. Acionar políticas judiciais para corrigir essas falhas de regulamentação tiraria oxigênio social de grupos armados não estatais, em geral, e, em particular, as organizações criminosas.

Paradoxalmente, os juízes "fracos" ou "ineficazes" podem ficar à deriva devido a "serviços" de resolução informal de conflitos que atendem à maioria dos conflitos legais dentro de uma sociedade, representando assim uma fonte de inércia institucional, bloqueando reformas judiciais muito necessárias. Em outras palavras, a fraqueza do Estado é, por vezes, "contagiosa" e sistemas judiciários fracos podem assim permanecer porque seus funcionários podem ter falta de razões para buscar reformas das suas instituições, uma vez que podem canalizar casos para o domínio informal, assim utilizando MARD como uma válvula de escape para o sistema judicial formal. Os benefícios e ganhos ilegais da corrupção política e judicial criam mais resistência às reformas judiciais que reforçam a governança no meio dessas válvulas de escape, proporcionadas pela resolução informal de litígios, tanto legais como ilegais. No entanto, experiências internacionais, como, por exemplo, na Colômbia e na Itália, mostram que esse impasse paradoxal pode ser superado por meio de reformas do sistema eleitoral e de financiamento de campanha política, de reformas legais fortemente pressionadas por iniciativas unificadas da sociedade civil. As experiências desses países foram abordadas em Buscaglia, Dakolias \& Ratliff, em Buscaglia \& Dakolias e em Buscaglia. ${ }^{79}$

${ }^{79}$ Cf. BUSCAGLIA, Edgardo; DAKOLIAS, Maria; RATLIFF, William. Judicial Reform in Latin America: a Framework for National Development. Stanford, CA: Hoover Institution Press, 1995; BUSCAGLIA, Edgardo; DAKOLIAS, Maria. Comparative International Study of Court Performance Indicators: A Descriptive and Analytical Account. The World Bank (Legal and Judicial Reform Unit), Report No. 20.177, 1999; BUSCAGLIA, Edgardo. Introduction to law and economics of development. In: Edgardo Buscaglia; William Ratliff; Robert Cooter (eds.). The Law and Economics of Development. Greenwich, CT: JAI Press, 1997; BUSCAGLIA, Edgardo. Judicial Corruption in Developing Countries: Its Causes and Economic Consequences. Stanford, CA: Hoover Institution Press, 1999; BUSCAGLIA, Edgardo. Vacíos de Poder en Mexico. Ciudad de México, DF: Random House Mondadori, 2013; e BUSCAGLIA, Edgardo. Dispute resolution mechanisms provided by violent non-state actors: An international comparative analysis of causes and consequences. In: Stefano Ruzza; Anja Jakobi; Charles Geisler (eds.). Non-State Challenges in a Re-Ordered World: The Jackals of Westphalia. London: Routledge, 2015. Experiências internacionais que 
Uma das principais conclusões deste trabalho é que a maior eficiência dos órgãos judiciais supranacionais e nacionais em cooperar e desmantelar, por meio de recursos para garantir o poder de mercado derivado da integração vertical de associações criminosas, também representa uma maneira de abordar e suprir as lacunas institucionais e resgatar o tecido social usado por essas organizações criminosas para proteger suas operações ilícitas. Isso faz com que as reformas judiciais voltadas para confisco de ativos criminosos e civis sejam uma ferramenta poderosa para contrariar os fundamentos sociais e políticos do crime organizado.

\title{
VI. REFERÊNCIAS
}

\author{
ACEMOGLU, Daron; ROBINSON, James A. Why Nations Fail: the \\ origins of power, prosperity, and poverty. New York, NY: Crown \\ Publishers, 2012.
}

ARIAS, Enrique Desmond; RODRIGUES, Corinne Davis. The Myth of Personal Security: Criminal Gangs, Dispute Resolution, and Identity in Rio de Janeiro's Favelas. Latin American Politics \& Society, Vol. 48, 4, 2006.

fogem a este impasse paradoxal são abordadas em BUSCAGLIA, Edgardo. Legal and Economic Development: The Missing Links. Journal of Interamerican Studies and World Affairs, Vol. 35, 4, 1994; e BUSCAGLIA, Edgardo. On best and not so good practices for addressing high-level political corruption worldwide: an empirical assessment. In: Susan Rose-Ackerman; Tina Søreide (eds.). International Handbook on the Economics of Corruption, Volume Two. Northampton, MA: Edward Elgar Publishing, 2011. As reformas da legislação eleitoral impulsionadas pelas iniciativas da sociedade civil de forma ascendente, por exemplo, na Colômbia e na Itália, foram capazes de "atualizar" e renovar a composição das elites políticas para "votar" por reformas judiciais que abordam o confisco de ativos criminais ligados ao crime organizado e à corrupção política. 
BERNSTEIN, Lisa. Merchant Law in a Merchant Court: Rethinking the Code's Search for Immanent Business Norms. University of Pennsylvania Law Review, Vol. 144, 5, 1996.

BIROL, Aline Pedra Jorge; DAL RI, JR., Arno. The Role of Organized Crime in Informal Justice Systems. Uluslararası Güvenlik ve Terörizm Dergisi, Vol. 2, 1, 2011.

BUSCAGLIA, Edgardo. An analysis of judicial corruption and its causes: an objective governing-based approach. International Review of Law and Economics, Vol. 21, 2, 2001.

BUSCAGLIA, Edgardo. Dispute resolution mechanisms provided by violent non-state actors: An international comparative analysis of causes and consequences. In: Stefano Ruzza; Anja Jakobi; Charles Geisler (eds.). Non-State Challenges in a Re-Ordered World: The Jackals of Westphalia. London: Routledge, 2015.

BUSCAGLIA, Edgardo. Institutional Factors Determining the Gap between Laws in the Books versus Laws in Action: An Analytical Framework for Improving Judicial Effectiveness. In: David Linnan (ed.). Legitimacy, Legal Development and Change: Law and Modernization Reconsidered. London: Routledge, 2016.

BUSCAGLIA, Edgardo. Introduction to law and economics of development. In: Edgardo Buscaglia; William Ratliff; Robert Cooter (eds.). The Law and Economics of Development. Greenwich, CT: JAI Press, 1997.

BUSCAGLIA Edgardo. Investigating the links between Access to Justice and Governance Factors: An objective indicators' approach. Global Programme against Corruption Research and Scientific Series (United Nations Center for International Crime Prevention), No. CICP-13, 2001. 
BUSCAGLIA, Edgardo. Judicial Corruption in Developing Countries: Its Causes and Economic Consequences. Stanford, CA: Hoover Institution Press, 1999.

BUSCAGLIA, Edgardo. Legal and Economic Development: The Missing Links. Journal of Interamerican Studies and World Affairs, Vol. 35, 4, 1994.

BUSCAGLIA, Edgardo. On best and not so good practices for addressing high-level political corruption worldwide: an empirical assessment. In: Susan Rose-Ackerman; Tina Søreide (eds.). International Handbook on the Economics of Corruption, Volume Two.

Northampton, MA: Edward Elgar Publishing, 2011.

BUSCAGLIA, Edgardo. Vacíos de Poder en Mexico. Ciudad de México, DF: Random House Mondadori, 2013.

BUSCAGLIA, Edgardo; DAKOLIAS, Maria. Comparative International Study of Court Performance Indicators: A Descriptive and Analytical Account. The World Bank (Legal and Judicial Reform Unit), Report No. 20.177, 1999.

BUSCAGLIA, Edgardo; DAKOLIAS, Maria; RATLIFF, William. Judicial Reform in Latin America: a Framework for National Development. Stanford, CA: Hoover Institution Press, 1995.

BUSCAGLIA, Edgardo; GONZÁLEZ RUIZ, Samuel. The Factor of Trust and the Importance of Inter-Agency Cooperation in the Fight against Transnational Organised Crime: The US-Mexican Example. The Management of Border Security in NAFTA: Imagery, Nationalism, and the War on Drugs, Vol. 15, 1, 2005. 
BUSCAGLIA, Edgardo; RATLIFF, William. War and Lack of Governance in Colombia: Narcos, Guerrillas and U.S. Policy. Stanford, CA: Hoover Institution Press, 2001.

BUSCAGLIA, Edgardo; STEPHAN, Paul. An Empirical Assessment of the Impact of Formal versus Informal Dispute Resolution on Poverty: a Governance-Based Approach. International Review of Law \& Economics, Vol. 25, 1, 2005.

BUSCAGLIA, Edgardo; VAN DIJK, Jan. Controlling Organized Crime and Corruption in the Public Sector. Forum on Crime and Society, Vol. 3, 1-2, 2003.

\section{COALITION TO STOP THE USE OF CHILD SOLDIERS. Mai Mai} Child Soldier Recruitment and Use: Entrenched and unending. London: Coalition to Stop the Use of Child Soldiers, 2010. Disponível em: $<$ https://www.childsoldiers.org/Handlers/Download.ashx?IDMF=ec1854f5-e25b-4176-a725e2f2e2cc841b>. Acesso em: 15 de fevereiro de 2018.

COBURN, Noah; DEMPSEY, John. Informal dispute resolution in Afghanistan. United States Institute of Peace, Special Report No. 247, 2010.

DE SOTO, Hernando. The Mystery of Capital: Why Capitalism Triumphs in the West and Fails Everywhere Else. New York, NY: Basic Books, 2000.

DE SOTO, Hernando. The Other Path: The Invisible Revolution in the Third World. New York, NY: Harper \& Row, 1989.

EUROPEAN PARLIAMENT. The Need for New EU Legislation Allowing the Assets Confiscated from Criminal Organizations to be Used for Civil Society and in Particular for Social Purposes. Brussels: 
European Parliament, 2012. Disponível em:

$<\underline{\text { http://www.europarl.europa.eu/document/activities/cont/201206/20120 }}$ 627ATT47783/20120627ATT47783EN.pdf > . Acesso em: 12 de fevereiro de 2018.

FARER, Tom. (ed). Transnational Crime in the Americas: An InterAmerican Dialogue Book. New York, NY: Routledge, 1999.

GAMBETTA, Diego. The Sicilian Mafia: The Business of Private Protection. Cambridge, MA: Harvard University Press, 1993.

GONZÁLEZ RUIZ, Samuel; MENDIETA JIMÉNEZ, Ernesto; BUSCAGLIA, Edgardo; MORENO HERNANDEZ, Moisés. El Sistema de Justicia Penal y su Reforma: Teoría y Práctica. $2^{\underline{a}}$ ed. Ciudad de México: Fontamara, 2006.

GRANGER, Clive. Investigating Causal Relations by Econometric Models and Cross-Spectral Methods. Econometrica, Vol. 37, 3, 1969.

GREIF, Avner; MILGROM, Paul; WEINGAST, Barry. Coordination, Commitment and Enforcement: The Case of the Merchant Guild. Journal of Political Economy, Vol. 102, 4, 1994.

GROSSMAN, Sanford; HART Oliver. The Costs and Benefits of Ownership: A Theory of Vertical and Lateral Integration. Journal of Political Economy, Vol. 94, 4, 1986.

HAYEK, Friedrich. Law, Legislation and Liberty, Vol. 1: Rules and Order. Chicago, IL: Chicago University Press, 1973.

HUDSON, Rex. Terrorist and Organized Crime Groups in the TriBorder Area (TBA) of South America. Washington, DC: Federal Research Division, Library of Congress, 2003. 
JACOBY, Sidney. Access to Justice. The American Journal of Comparative Law, Vol. 29, 3, 1981. Resenha de: CAPPELLETTI, Mauro; GARTH, Bryant; WEISNER, John; KOCH, Klaus-Friedrich. Access to Justice. Milan: Giuffrè, 1979.

JAMIESON, Neil, MOI, Stephen, \& CHEROT, Jason. Acting outside the box: The emerging dispute resolution centres developing innovative ways to attract business. Legal Week, 07 jun. 2012. Disponível em: $<$ http://www.legalweek.com/sites/legalweek/2012/06/07/acting-outsidethe-box-the-emerging-dispute-resolution-centres-developinginnovative-ways-to-attract-business/>. Acesso em: 12 de fevereiro de 2018.

MILHAUPT, Curtis; WEST, Mark. The Dark Side of Private Ordering: An Institutional and Empirical Analysis of Organized Crime. University of Chicago Law Review, Vol. 67, 1, 2000.

NORTH, Douglass. Institutions, Institutional Change and Economic Performance. Cambridge, MA: Cambridge University Press, 1990.

PEDROSO, João; TRINCÃO, Catarina. The (Re)birth of the Justice of the Peace: Democratic or Technocratic Justice Reform? The Experiences of Italy, Spain, Brazil and Portugal. Beyond Law, Vol. 19, 27, 2004.

SANTOS, Boaventura de Souza. The Law of the Oppressed: the Construction and Reproduction of Legality in Pasárgada. Law \& Society Review, Vol. 12, 1, 1977.

SCHÄRF, Wilfried. Non-State Justice Systems in Southern Africa: How Should Governments Respond? In: Workshop on Working with NonState Justice Systems. Paper apresentado. London: University of Bermingham, 2003. Disponível em: $<$ http://www.gsdrc.org/docs/open/DS35.pdf $>$. Acesso em: 12 de fevereiro de 2018. 
SCHELLING, Thomas. What is the Business of Organized Crime? The American Scholar, Vol. 40, 4, 1971.

SUNG, Hung-En. State Failure, Economic Failure, and Predatory Organized Crime: A Comparative Analysis. Journal of Research in Crime and Delinquency, Vol. 41, 2, 2004.

UNITED NATIONS OFFICE ON DRUGS AND CRIME. Transnational Organized Crime in the West African Region. New York, NY: United Nations, 2005.

WAHYONO, Pujo. Transnational Crime and Security Threats in Indonesia. USAWC Strategy Research Project. Carlisle Barracks, PA: U.S. Army War College, 2010. Disponível em: $<$ http://www.economicsejournal.org/economics/discussionpapers/2007-3/at download/file>. Acesso em: 12 de fevereiro de 2018.

WILLIAMSON, Oliver. The Economics of Organization: The Transaction Cost Approach. The American Journal of Sociology, Vol. 87, 3, 1981.

WILLIAMSON, Oliver. Transaction Costs Economics: An Introduction. Economics Discussion Papers, No. 2007-3, 2007. Disponível em:

$<$ http://www.economics-ejournal.org/economics/discussionpapers/20073/at download/file>. Acesso em: 12 de fevereiro de 2018.

WOJKOWSKA, Ewa. Doing justice: How Informal Justice Systems can contribute. New York, NY: United Nations Development Programme, 2006. 
A Integração Vertical do Crime Organizado Relacionada à Corrupção Política: Análise Jurídico-Econométrica do Confisco de Bens e Direitos Humanos The Vertical Integration of Organized Crime Linked to Political Corruption: An Economic-Jurimetric Analysis of Asset Forfeitures and Human Rights Submetido em: 2017-09-25

Aceito em: 2018-01-30 